\title{
Polyclad phylogeny persists to be problematic
}

\author{
Isabel L. Dittmann ${ }^{1}$ (ID) $\cdot$ Daniel Cuadrado ${ }^{2} \cdot$ Maria Teresa Aguado $^{3,4} \cdot$ Carolina Noreña $^{2} \cdot$ Bernhard Egger $^{1}$ (I)
}

Received: 12 April 2019 / Accepted: 14 August 2019/Published online: 16 September 2019

(C) The Author(s) 2019

\begin{abstract}
Two conflicting morphological approaches to polyclad systematics highlight the relevance of molecular data for resolving the interrelationships of Polycladida. In the present study, phylogenetic trees were reconstructed based on a short alignment of the 28S rDNA marker gene with 118 polyclad terminals (24 new) including 100 different polyclad species from 44 genera and 22 families, as well as on a combined dataset using 18S and 28S rDNA genes with 27 polyclad terminals (19 new) covering 26 different polyclad species. In both approaches, Theamatidae and Cestoplanidae were included, two families that have previously been shown to switch from Acotylea to Cotylea. Three different alignment methods were used, both with and without alignment curation by Gblocks, and all alignments were subjected to Bayesian inference and maximum likelihood tree calculations. Over all trees of the combined dataset, an extended majority-rule consensus tree had weak support for Theamatidae and Cestoplanidae as acotyleans, and also the cotylean genera Boninia, Chromyella and Pericelis appeared as acotyleans. With the most inclusive short $28 \mathrm{~S}$ dataset, on the other hand, there is good support for the aforementioned taxa as cotyleans. Especially with the short $28 \mathrm{~S}$ matrix, taxon sampling, outgroup selection, alignment method and curation, as well as model choice were all decisive for tree topology. Well-supported parts of the phylogeny over all trees include Pseudocerotoidea, Prosthiostomoidea, Stylochoidea, Leptoplanoidea and Cryptoceloidea, the latter three with new definitions. Unstable positions in the tree were found not only for Theamatidae, Cestoplanidae, Boninia, Chromyella and Pericelis, but also for Anonymus, Chromoplana and Cycloporus.
\end{abstract}

Keywords Platyhelminthes $\cdot$ Polycladida $\cdot$ Cotylea $\cdot$ Acotylea $\cdot$ Molecular phylogenetics $\cdot$ Systematics

\section{Introduction}

Due to their colourful appearance, polyclad flatworms are among the most conspicuous members of the phylum Platyhelminthes, yet these animals are relatively poorly

Electronic supplementary material The online version of this article (https://doi.org/10.1007/s13127-019-00415-1) contains supplementary material, which is available to authorized users.

Bernhard Egger

bernhard.egger@uibk.ac.at

1 Institute of Zoology, University of Innsbruck, Technikerstr. 25, 6020 Innsbruck, Austria

2 Museo Nacional de Ciencias Naturales (CSIC), José Gutiérrez Abascal 2, 28006 Madrid, Spain

3 Animal Evolution and Biodiversity, Johann-Friedrich-Blumenbach Institute for Zoology \& Anthropology, Georg-August-Universität Göttingen, Göttingen, Germany

4 Centro de Investigación en Biodiversidad y Cambio Global (CIBC-UAM). Departamento de Biología, Facultad de Ciencias, Universidad Autónoma de Madrid, Cantoblanco, Madrid, Spain studied (Bahia et al. 2017). Usually, polyclads occur in diverse marine habitats, such as under coastal stones, on reefs and in interstitial spaces (Hyman 1951; Prudhoe 1985; CuriniGalletti et al. 2008). About 800 to 1000 species of polyclads are currently recognised (Rawlinson 2008; Martín-Durán and Egger 2012).

The phylogenetic position of Polycladida within Platyhelminthes used to be very controversial (Bahia et al. 2017). Only recently, Polycladida have been consistently recovered as sister group to Prorhynchida (a group harbouring only freshwater dwellers), forming the Amplimatricata, which is the sister group of all other Trepaxonemata (Egger et al. 2015; Laumer et al. 2015; Laumer and Giribet 2017).

Lang (1884) was the first to distinguish between two groups of 'marine planarians', the Tricladida and the Polycladida. He further grouped the Polycladida into forms with a ventral sucker behind the genital openings (Cotylea), and those without (Acotylea). This classification system persists after some modifications (e.g. Laidlaw 1903; Bock 1913; Hyman 1953; Marcus and Marcus 1966) until today, and in the 1980s, Faubel $(1983,1984)$ and Prudhoe (1985) separately published monographs attempting to further clarify the 
interrelationships of polyclads on morphological grounds, using genital organs, especially the organisation of the prostatic vesicle (Faubel 1983, 1984), the position of eyes and tentacles (Prudhoe 1985), or the pharynx organisation (Faubel 1983, 1984; Prudhoe 1985) as main systematic characters - however, the resulting classifications were largely incongruent. Interestingly, Faubel (1984) considered both Cotylea and Acotylea as not being monophyletic, but retained the names for taxonomic consistency. Prudhoe (1985) was also aware of problems with the classification and he cited several cases, where some families, such as Enantiidae and Boniniidae, have features fitting both to Cotylea and Acotylea.

For more than 30 years, these two conflicting systems have been in use by polycladologists (a term coined by J. Bahia, personal communication), stressing the need of a unifying system, based on morphology, on molecules, or both. The first molecular phylogenetic reconstruction of polyclad interrelationships was using a partial sequence of about 350 nucleotides of the marker molecule 28S (large nuclear ribosomal subunit) and was focussed on the family Pseudocerotidae, with Pericelis as the cotylean sister group of Pseudocerotidae (Litvaitis and Newman 2001). Another molecular phylogenetic analysis of Polycladida based on partial $28 \mathrm{~S}$ sequences (about $900 \mathrm{nt}$ long) included just eight cotylean and six acotyleans - Cotylea was not recovered as monophyletic, since the cotylean species Pericelis cata appeared outside the other Cotylea as sister group of Acotylea, while Cestoplana rubrocincta emerged as an acotylean as in Faubel's and Prudhoe's systems (Rawlinson et al. 2011). With a very similar dataset, Rawlinson and Stella (2012) recovered both, Pericelis and Cestoplana, as basally branching cotyleans, thereby stressing the problematic position of these taxa. In a flatworm-wide phylogenetic study based on four genes, the acotylean Theama was grouped with the remaining Cotylea, not with the Acotylea (Laumer and Giribet 2014), which was corrobarated in a transcriptomic study in the following year (Laumer et al. 2015).

In 2017, three large molecular phylogenies of polyclads were published, two with different stretches of the $28 \mathrm{~S}$ marker gene (Bahia et al. 2017; Tsunashima et al. 2017), and one with mitochondrial genes (Aguado et al. 2017). Of these studies, only Bahia et al. dealt with the aforementioned problematic taxa, namely Pericelis, Cestoplana and Theama - all of them showing up as cotyleans in their tree (Bahia et al. 2017). However, this study only used a single alignment method and a single model with relatively low bootstrap support levels, so the reliability of the provided reconstruction remained unclear. During the review phase of this manuscript, another publication using the $28 \mathrm{~S}$ marker gene was published (Litvaitis et al. 2019).

In the present study, we also have used partial 28S rDNA sequences, as well as a combined dataset of longer $18 \mathrm{~S}$ and
28S sequences of a wide systematic range of polyclads. Most importantly, we have applied three different, widely used alignment algorithms and two different statistical approaches for tree reconstruction to test the stability and reliability of molecular phylogenies using one or two genes, and also, when possible, to infer relationships between groups based on a bigger data set.

\section{Material and methods}

\section{Animal collection, identification of species and transcriptome data}

An overview of newly generated and published sequences is provided in Table 1. For most collected material, tissue was stored in 99\% ethanol, and histological sections were made as described by Aguado et al. (2017) and Dittmann et al. (2019). Several published polyclad transcriptomes (Egger et al. 2015, Laumer et al. 2015) were searched for $18 \mathrm{~S}$ and $28 \mathrm{~S}$ sequences (see Table 1) using BLAST (Altschul et al. 1990).

\section{DNA extraction, PCR amplification and sequencing}

For all specimens, DNA was extracted from a small piece of ethanol-preserved marginal tissue. DNA extraction was performed following phenol-chloroform protocols (Sambrook et al. 1989; Chen et al. 2010). Concentration and possible contamination of extracted DNA were checked using NanoDrop (NanoDrop Fluorospectrometer Thermo Fisher Scientific, USA). PCRs were performed in a total volume of $25 \mu \mathrm{l}$ or $50 \mu \mathrm{l}$. 18S rDNA was amplified either in two overlapping fragments using the published primer combinations $4 \mathrm{fb}+1806 \mathrm{R}$ (ca. $1200 \mathrm{bp}$ ) and $5 \mathrm{fk}+\mathrm{S} 30$ (ca. $900 \mathrm{bp}$ ) (Larsson and Jondelius 2008) or in one approach using 18S1F+18S9R (ca. 1800 bp) (Álvarez-Presas et al. 2008). 28S rDNA was amplified with the primers 28 LSU5 fw + L1642R (ca.1450 bp) or 28S_1F + 28S_6R (ca. 1600 bp) (Larsson and Jondelius 2008). PCR was performed using a 'Touch Down' protocol using the following protocol: $5 \mathrm{~min}$ of initial denaturation at $94{ }^{\circ} \mathrm{C} ; 30 \mathrm{~s}$ of denaturation at $94{ }^{\circ} \mathrm{C}$, annealing at $68-45^{\circ} \mathrm{C}$ for $30 \mathrm{~s}$, extension at $72{ }^{\circ} \mathrm{C}$ for $2 \mathrm{~min}$; 12 cycles; $30 \mathrm{~s}$ of denaturation at $94^{\circ} \mathrm{C}$, annealing at $45^{\circ} \mathrm{C}$ for $30 \mathrm{~s}$, extension at $72{ }^{\circ} \mathrm{C}$ for $2 \mathrm{~min} ; 23$ cycles; final extension at $72{ }^{\circ} \mathrm{C}$ for $10 \mathrm{~min}$, hold at $4{ }^{\circ} \mathrm{C}$. Successful products were purified using ExoSAP-IT (Affymetrix, USA), following manufacturer's protocol, or with the Wizard ${ }^{\circledR}$ SV gel and PCR clean-up system (Promega, USA) according to the manufacturer's quick protocol. PCR products were sequenced by CBMSO (Spain) or by Microsynth Austria GmbH, respectively. Sequences were assembled and edited by hand or using the software CLC Main Workbench 7 (Qiagen, Germany). 
Table 1 List of all species used in this study, including authorities, sample locations and accession or SRA numbers. In trees using only a single sequence of the same species, the first listed sequence was included, with the number omitted

\begin{tabular}{|c|c|c|c|c|c|c|}
\hline Species & & Authority & Location & 28Sshort6 & 18S28Slong & SRA \\
\hline Ilyella & gigas & (Schmarda 1859) & Japan & LC100080.1 & & \\
\hline Discocelis & tigrina & (Blanchard 1847) & Valencia, Spain & MN384690 & MN334200, MN384690 & \\
\hline Adenoplana & evelinae & Marcus 1950 & Brazil & KY263647.2 & & \\
\hline \multirow[t]{4}{*}{ Cestoplana } & rubrocincta 1 & (Grube 1840) & Naples, Italy & MN384689 & MN334198, MN384689 & \\
\hline & rubrocincta 2 & & Australia & HQ659009.1 & & \\
\hline & salar & Marcus 1949 & Brazil & KY263653.2 & & \\
\hline & techa & $\begin{array}{l}\text { Du Bois-Reymond Marcus } \\
1957\end{array}$ & Brazil & KY263652.2 & & \\
\hline Phaenocelis & medvedica & Marcus 1952 & Brazil & KY263701.2 & & \\
\hline \multirow[t]{2}{*}{ Echinoplana } & celerrima 1 & Haswell 1907 & Tunis, Tunisia & MN421930 & MN421936, MN421930 & SRS842092 \\
\hline & celerrima 2 & & Australia & HQ659020.1 & & \\
\hline \multirow[t]{3}{*}{ Hoploplana } & californica & Hyman 1953 & California & KC869850.1 & $\begin{array}{l}\text { KC869797.1, } \\
\text { KC869850.1 }\end{array}$ & \\
\hline & divae & Marcus 1950 & Brazil & KY263692.2 & & \\
\hline & villosa & (Lang 1884) & Japan & LC100076.1 & & \\
\hline \multirow[t]{3}{*}{ Leptoplana } & tremellaris 1 & (Müller 1773) & Cornwall, UK & MN421931 & MN421937, MN421931 & SRS842637 \\
\hline & tremellaris 2 & & Spain & KY263695.2 & & \\
\hline & sp. & & $\begin{array}{l}\text { Lizard Island } \\
\text { (Australia) }\end{array}$ & MN384693 & & \\
\hline \multirow[t]{4}{*}{ Notoplana } & australis 1 & (Laidlaw 1904) & Australia & AY157153.1 & $\begin{array}{l}\text { AJ228786.1 } \\
\text { AY157153.1 }\end{array}$ & \\
\hline & australis 2 & & Australia & HQ659015.1 & & \\
\hline & delicata & (Jacubowa 1906) & Japan & LC100088.1 & & \\
\hline & sp. & & Brazil & KY263651.2 & & \\
\hline \multirow[t]{4}{*}{ Notocomplana } & humilis & (Stimpson 1857) & Japan & LC100085.1 & & \\
\hline & japonica & (Kato 1937a) & Japan & LC100087.1 & & \\
\hline & koreana & (Kato 1937b) & Japan & LC100086.1 & & \\
\hline & sp. & & Japan & LC100089.1 & & \\
\hline Melloplana & ferruginea & (Schmarda 1859) & Florida & HQ659014.1 & & \\
\hline Comoplana & agilis & (Lang 1884) & Galicia, Spain & MN384685 & MN334199, MN384685 & \\
\hline Armatoplana & leptalea & (Marcus 1947) & Brazil & KY263648.2 & & \\
\hline Amemiyaia & pacifica & Kato 1944 & Japan & LC100077.1 & & \\
\hline \multirow[t]{2}{*}{ Theama } & mediterranea & Curini-Galletti et al. 2008 & Rovinj, Croatia & MN384705 & MN384707, MN384705 & \\
\hline & sp. & & Panama & KC869845.1 & $\begin{array}{l}\text { KC869792.1, } \\
\text { КC869845.1 }\end{array}$ & \\
\hline Callioplana & marginata & Stimpson1857 & Japan & LC100082.1 & & \\
\hline \multirow[t]{2}{*}{ Planocera } & multitentaculata & Kato 1944 & Japan & LC100081.1 & & \\
\hline & pellucida & (Mertens 1833) & Canary Island, Spain & MN384696 & MN334203, MN384696 & \\
\hline \multirow[t]{2}{*}{ Paraplanocera } & oligoglena & (Schmarda 1859) & Hawaii & KC869849.1 & $\begin{array}{l}\text { KC869796.1, } \\
\text { KC869849.1 }\end{array}$ & \\
\hline & sp. & & Greece & KY263699.2 & & \\
\hline Idioplana & australiensis & Woodworth 1898 & Australia & HQ659008.1 & & \\
\hline \multirow[t]{2}{*}{ Pseudostylochus } & obscurus & (Stimpson 1857) & Japan & LC100084.1 & & \\
\hline & sp. & & Japan & LC100083.1 & & \\
\hline \multirow[t]{5}{*}{ Stylochus } & ellipticus & (Girard 1850) & Woods Hole, USA & Suppl. File 1 & Suppl. File 1 & SRS913554 \\
\hline & ijimai & Yeri and Kaburaki 1918 & Japan & LC100079.1 & & \\
\hline & oculiferus & (Girard 1853) & Florida & HQ659007.1 & & \\
\hline & zebra & (Verrill 1882) & US Atlantic coast & AF342800.1 & $\begin{array}{l}\text { AF342801.1, } \\
\text { AF342800.1 }\end{array}$ & \\
\hline & sp. & & Peru & KY263743.2 & & \\
\hline Imogine & refertus & & Brazil & KY263694.2 & & \\
\hline
\end{tabular}


Table 1 (continued)

\begin{tabular}{|c|c|c|c|c|c|c|}
\hline \multicolumn{2}{|l|}{ Species } & \multirow{2}{*}{$\begin{array}{l}\text { Authority } \\
\text { Du Bois-Reymond Marcus } \\
1965\end{array}$} & \multirow[t]{2}{*}{ Location } & \multirow[t]{2}{*}{ 28Sshort6 } & \multirow[t]{2}{*}{ 18S28Slong } & \multirow[t]{2}{*}{ SRA } \\
\hline & & & & & & \\
\hline & stellae & Marquina et al. 2014 & Valencia, Spain & MN384692 & MN334201, MN384692 & \\
\hline Leptostylochus & gracilis & Kato 1934 & Japan & LC100078.1 & & \\
\hline \multirow[t]{7}{*}{ Cycloporus } & gabriellae 1 & Marcus 1950 & Brazil & KY263656.2 & & \\
\hline & gabriellae 2 & & & KY263658.2 & & \\
\hline & variegatus 1 & Kato 1934 & Brazil & KY263657.2 & & \\
\hline & variegatus 2 & & Spain & KY263659.2 & & \\
\hline & variegatus 3 & & Brazil & KY263660.2 & & \\
\hline & variegatus 4 & & Brazil & KY263661.2 & & \\
\hline & japonicus & Kato 1944 & Japan & LC100092.1 & & \\
\hline \multirow[t]{5}{*}{ Maritigrella } & crozieri 1 & (Hyman 1939) & Florida Keys, USA & MN421933 & MN421939, MN421933 & SRS844631 \\
\hline & crozieri 2 & & $\begin{array}{l}\text { Aquaria in Virginia, } \\
\text { USA }\end{array}$ & HQ659013.1 & & \\
\hline & crozieri 3 & & Florida & KY263686.2 & & \\
\hline & fuscopunctata & (Prudhoe 1978) & Maltese coast & KU674837.1 & & \\
\hline & newmanae & Bolaños et al. 2007 & Belize & EF514798.1 & & \\
\hline \multirow[t]{2}{*}{ Prostheceraeus } & roseus & Lang 1884 & Tenerifa & KY263688.2 & & \\
\hline & vittatus & (Montagu 1815) & unknown & Suppl. File 1 & Suppl. File 1 & SRS913668 \\
\hline Stylostomum & ellipse & (Dalyell 1853) & Punat, Croatia & MN384704 & MN334208, MN384704 & \\
\hline Euryleptodes & galikias & Noreña et al. 2014 & Galicia, Spain & MN384691 & & \\
\hline \multirow[t]{5}{*}{ Prosthiostomum } & grande & Stimpson 1857 & Japan & LC100090.1 & & \\
\hline & siphunculus 1 & (Delle Chiaje 1822) & Barcelona, Spain & MN421934 & MN421940, MN421934 & SRS842699 \\
\hline & siphunculus 2 & & Asturias, Spain & MN384697 & MN334204, MN384697 & \\
\hline & siphunculus 3 & & Spain & HQ659012.1 & & \\
\hline & vulgaris & Kato 1938 & Japan & LC100091.1 & & \\
\hline Amakusaplana & acroporae & Rawlinson et al. 2011 & Aquaria US East Coast & HQ659010.1 & & \\
\hline Lurymare & katoi & Poulter 1975 & $\begin{array}{r}\text { Lizard Island } \\
\text { (Australia) }\end{array}$ & MN384694 & & \\
\hline \multirow[t]{3}{*}{ Enchiridium } & evelinae & Marcus 1949 & Brazil & KY263662.2 & & \\
\hline & sp. 1 & & $\begin{array}{r}\text { Lizard Island } \\
\text { (Australia) }\end{array}$ & MN384686 & & \\
\hline & sp. 2 & & Santa Helena Island & KY263665.2 & & \\
\hline Chromyella & sp. & & Panama & КC869848.1 & $\begin{array}{l}\text { KC869795.1, } \\
\text { KC869848.1 }\end{array}$ & \\
\hline \multirow[t]{2}{*}{ Anonymus } & ruber & Cuadrado et al. 2017 & Canary Island, Spain & MN384687 & MN334197, MN384687 & \\
\hline & virilis & Lang 1884 & Canary Island, Spain & MN384688 & & \\
\hline Boninia & divae & Marcus and Marcus 1968 & Panama & KC869846.1 & $\begin{array}{l}\text { KC869793.1, } \\
\text { KC869846.1 }\end{array}$ & \\
\hline Chromoplana & sp. & & Panama & KC869847.1 & $\begin{array}{l}\text { KC869794.1, } \\
\text { KC869847.1 }\end{array}$ & \\
\hline \multirow[t]{5}{*}{ Pericelis } & byerleyana & (Collingwood 1876) & Red Sea & MH047291.1 & & \\
\hline & cata 1 & Marcus and Marcus 1968 & unknown & EU679114.1 & & \\
\hline & cata 2 & & Brazil & KY263700.2 & & \\
\hline & orbicularis & (Schmarda 1859) & unknown & EU679116.1 & & \\
\hline & tectivorum & Dittmann et al. 2019 & $\begin{array}{l}\text { Aquaria Innbruck, } \\
\text { Austria }\end{array}$ & MK181524 & MN334202, MK181524 & \\
\hline \multirow[t]{4}{*}{ Pseudoceros } & astorum & Bulnes and Torres 2014 & Brazil & KY263737.2 & & \\
\hline & bicolor 1 & Verrill 1902 & Belize & GQ398095.1 & & \\
\hline & bicolor 2 & & Brazil & KY263732.2 & & \\
\hline & $\begin{array}{l}\text { bicolor } \\
\quad \text { marcusorum }\end{array}$ & Litvaitis et al. 2010 & Belize & GQ398098.1 & & \\
\hline
\end{tabular}


Table 1 (continued)

\begin{tabular}{|c|c|c|c|c|c|c|}
\hline \multicolumn{2}{|l|}{ Species } & \multirow[t]{2}{*}{ Authority } & \multirow{2}{*}{$\begin{array}{l}\text { Location } \\
\text { Brazil }\end{array}$} & \multirow{2}{*}{$\begin{array}{l}\text { 28Sshort6 } \\
\text { KY263729.2 }\end{array}$} & \multirow[t]{2}{*}{ 18S28Slong } & \multirow[t]{2}{*}{ SRA } \\
\hline & cf bicolor & & & & & \\
\hline & bimarginatus & Meixner 1907 & $\begin{array}{r}\text { Lizard Island } \\
\text { (Australia) }\end{array}$ & MN384700 & MN334207, MN384700 & \\
\hline & contrarius & Newman and Cannon 1995 & Papua New Guinea & KY263728.2 & & \\
\hline & harrisi & Bolaños et al. 2007 & Panama & EF514802.1 & & \\
\hline & jebborum & Newman and Cannon 1994 & $\begin{array}{r}\text { Lizard Island } \\
\text { (Australia) }\end{array}$ & MN384701 & & \\
\hline & cf maximus & Lang 1884 & Spain & KY263708.2 & & \\
\hline & nipponicus & Kato 1944 & Japan & LC100096.1 & & \\
\hline & periaurantius & Newman and Cannon 1994 & $\begin{array}{r}\text { Lizard Island } \\
\text { (Australia) }\end{array}$ & MN384702 & & \\
\hline & rawlinsonae 1 & Bolaños et al. 2007 & Bahamas & GQ398101.1 & & \\
\hline & rawlinsonae 2 & & Brazil & KY263733.2 & & \\
\hline & stimpsoni & Newman and Cannon 1998 & $\begin{array}{r}\text { Lizard Island } \\
\text { (Australia) }\end{array}$ & MN384703 & & \\
\hline & velutinus 1 & (Blanchard 1847) & Spain & KY263726.2 & & \\
\hline & velutinus 2 & & Japan & LC100095.1 & & \\
\hline \multirow[t]{11}{*}{ Pseudobiceros } & bedfordi & (Laidlaw 1903) & Papua New Guinea & KY263715.2 & & \\
\hline & caribbensis & Bolaños et al. 2007 & Curaçao & EF514804.1 & & \\
\hline & evelinae & (Marcus 1950) & Brazil & KY263716.2 & & \\
\hline & flowersi & Newman and Cannon 1997 & $\begin{array}{r}\text { Lizard Island } \\
\text { (Australia) }\end{array}$ & MN384698 & MN334205, MN384698 & \\
\hline & hancockanus & (Collingwood 1876) & $\begin{array}{r}\text { Lizard Island } \\
\text { (Australia) }\end{array}$ & MN384699 & MN384706, MN384699 & \\
\hline & nigromarginatus & (Yeri \& Kaburaki 1918) & Japan & LC100097.1 & & \\
\hline & pardalis 1 & (Verrill 1900) & Panama & EF514807.1 & & \\
\hline & pardalis 2 & & Brazil & KY263723.2 & & \\
\hline & splendidus & (Lang 1884) & Florida & HQ659016.1 & & \\
\hline & wirtzi & Bahia and Schroedl 2016 & Senegal & KY263725.2 & & \\
\hline & sp. & & Santa Helena Island & KY263724.2 & & \\
\hline Maiazoon & orsaki & Newman and Cannon 1996 & Papau New Guinea & KY263697.2 & & \\
\hline \multirow[t]{4}{*}{ Thysanozoon } & alagoensis & Bahia et al. 2015 & Brazil & KY263747.2 & & \\
\hline & brocchii 1 & (Risso 1818) & Philip Island, Australia & HQ659017.1 & & \\
\hline & brocchii 2 & & Brazil & KY263744.2 & & \\
\hline & raphaeli & Bolaños et al. 2007 & Panama & EF514809.1 & & \\
\hline Yungia & sp. & & Florida & HQ659018.1 & & \\
\hline Phrikoceros & mopsus & (Marcus 1952) & Brazil & KY263707.2 & & \\
\hline Monobiceros & langi & Faubel 1984 & Spain & KY263710.2 & & \\
\hline Macrostomum & lignano & Ladurner et al. 2005 & & MN421932 & MN421938, MN421932 & SRS842645 \\
\hline Xenoprorhynchus & sp. & & & KC869852.1 & $\begin{array}{l}\text { KC869813.1, } \\
\text { KC869852.1 }\end{array}$ & \\
\hline
\end{tabular}

\section{Datasets for phylogenetic analyses}

We made eight different single gene sequence collections of 'short' $28 \mathrm{~S}$ sequences (see Table 1 for accession numbers of all newly generated and used published data). In general, we only used one sequence per species from the same authors.

The first sequence collection used 108 polyclad terminals (including the first, gappy version of sequences published by Bahia et al. 2017 on NCBI, which was corrected and reuploaded by
Bahia et al. in 2019 with a non-gappy version), 20 of which were generated by us, and Macrostomum lignano as an outgroup ('28Sshort1'), while all subsequent 'short' 28S sequence collections worked with the updated second sequence versions of Bahia et al. (2017): '28Sshort2' added Cycloporus japonicus, two Pericelis and four pseudocerotoid sequences, while '28Sshort3' only included all (updated) sequences of '28Sshort1'.

Variations of '28Sshort2' included only Xenoprorhynchus sp. ('28Sshort2X') or both Xenoprorhynchus sp. and 
Macrostomum lignano ('28Sshort2XM') as outgroups. '28Sshort4' is identical to '28Sshort3', except the removal of Chromoplana sp., whereas in '28Sshort5', we also removed Cycloporus variegatus. Finally, for '28Sshort6', we used '28Sshort2' sequences and included all available sequences of Cycloporus variegatus (four sequences) and Cycloporus gabriellae (two sequences). Most of the shown trees deal with the last sequence collection, which includes 118 polyclad terminals ( 24 sequences provided by us), covering 100 polyclad species.

Additionally, we made a combined dataset of 'long' $18 \mathrm{~S}$ and $28 \mathrm{~S}$ sequences ('18S28Slong'), including 27 polyclad terminals (19 of which were newly generated) and Macrostomum lignano as an outgroup.

Sequences for each gene were separately aligned using three methods: MUSCLE v3.8.31 (Edgar 2004), MAFFT QINS-i and MAFFT E-INS-i v7.310 (Katoh and Standley 2013). They were manually trimmed, and in the case of the combined dataset, concatenated. For several alignments, we also used Gblocks with the least stringent settings (Castresana 2000). Conversion of fasta alignments to Nexus and Phylip formats was done using ALTER (Glez-Peña et al. 2010).

Two different approaches for phylogenetic reconstructions were pursued: maximum likelihood (ML) reconstructions using RAxML (Stamatakis 2014), and Bayesian inference (BI) with MrBayes (Ronquist et al. 2012). The best models $(\mathrm{GTR}+\mathrm{I}+\mathrm{G})$ were determined with jModelTest v2.1.10 using the Akaike Information Criterion AIC(c) (Posada 2008).

For ML trees, between 500 and 10,000 tree searches were performed, and between 500 and 1000 separate bootstrap replicates. At least 5-10 million generations were calculated for BI trees, or more until convergence (average standard deviation of split frequences $<0.01$ ) was reached. For extended majority-rule consensus trees, we used RAxML with the concatenated trees of BI and ML analyses of the 28Sshort6 dataset (see Table 2). Phylogenetic trees were visualised in Figtree (http://tree.bio.ed.ac.uk/software/figtree/) and adapted in Inkscape (https://inkscape.org/) and Adobe Illustrator CS4.

The sequences generated during and/or analysed during the current study are available in the GenBank repository, under the accession numbers listed in Table 1 . The datasets generated during and/or analysed during the current study are available from the corresponding author on reasonable request.

\section{Results}

\section{Effects of model choice, alignment, outgroup selection and taxon sampling on tree topology}

We recovered varied results with our combined 18S28Slong matrix (see Table 2, Suppl. Figs. S1-12): without using Gblocks for alignment curation, three of the six phylogenetic reconstructions supported Cestoplanoidea, Chromoplanoidea, Periceloidea, Anonymidae and Chromoplana as cotyleans (Suppl. Figs. S5, S10, S11), while three trees rendered most of these taxa as acotyleans or polytomic (Suppl. Figs. S4, S6, $\mathrm{S} 12$ ). We have visualised these changes caused by model choice in Fig. 1. Using Gblocks, only the two trees based on a Q-INS-i alignment recovered Cestoplanoidea, Chromoplanoidea, Periceloidea, Anonymidae and Chromoplana as cotyleans (Suppl. Figs. S2,8). In both EINS-i trees and the ML MUSCLE tree, Anonymidae and Chromoplana are sister group of all other Polycladida, while in the BI MUSCLE tree, they are polytomic with Cotylea and Acotylea (see Table 2).

We continued our analyses with the first 28S-only dataset (28Sshort1) with many more taxa than available in the 18S28Slong dataset, including the first version of sequences published by Bahia et al. (2017). With this dataset, we calculated BI and ML trees based on three different alignments, and consistently (100\%) recovered Cestoplanoidea, Chromoplanoidea, Periceloidea, Anonymidae and Chromoplana as Cotylea. The corresponding MRE tree exhibited an identical topology as the BI MUSCLE tree shown in Fig. 2a. After obtaining the new sequence versions of Bahia et al. (2017) in January 2019, we recalculated all trees with the new sequences (and adding additional sequences, see 28Sshort2) and consistently (100\%) recovered the aforementioned groups as Acotylea, regardless of outgroup selection or alignment curation (Fig. 3).

We tested different parameters, always using a short $28 \mathrm{~S}$ dataset with BI MUSCLE with and without Gblocks for tree reconstruction. Using Gblocks, outgroup selection markedly changed other parts of the topology, such as Prosthiostomoidea alternating between Acotylea and Cotylea (Fig. 3). With only Xenoprorhynchus as outgroup, Chromoplana is the sister group of all other Polycladida (Fig. 3b), while with only Macrostomum as outgroup, Cycloporus variegatus takes the place of sister group of all other Polycladida (Fig. 3c). Using the same ingroup and outgroup taxa as in Fig. 3c, but without Gblocks, we recovered a topology with many basal polytomies (Fig. 3d). With both non-polyclad outgroups, a basal polytomy between Cycloporus variegatus, Euryleptidae and all other Polycladida was recovered (Fig. 3a). Prosthiostomidae are basally branching Acotylea with Macrostomum + Xenoprorhynchus, and only Macrostomum as outgroups. Xenoprorhynchus alone as outgroup provides a basal polytomy of Anonymus, Cotylea and Acotylea, except Chromoplana (Fig. 3b).

Consequently, we tested if the newly added sequences were responsible for the change in tree topology, especially of Cestoplanoidea, Chromoplanoidea, Periceloidea, Anonymidae and Chromoplana. We therefore removed all additional sequences compared to our first dataset leading to the 28Sshort3 alignment, and with the same alignment and 
Table 2 Summary and overview of all trees calculated with the 18S28Slong and the 28Sshort6 datasets. $M L$ maximum likelihood, $B I$ Bayesian inference, $M$ MUSCLE, $Q$ Q-INS-i, $E$ E-INS-i alignment, $G B$ with Gblocks, No GB without Gblocks alignment curation, $x$ yes, - no, $p$ polytomic, ? no data

Suppl. Fig. S

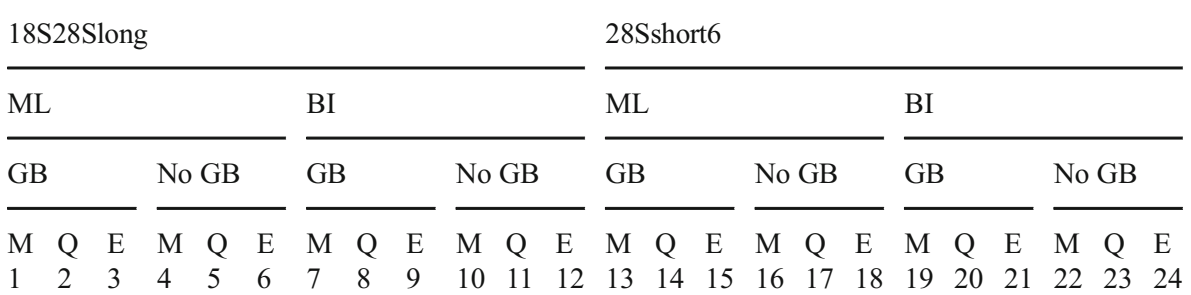

1. Cotylea and Acotylea sensu

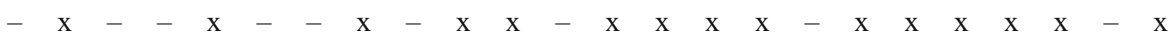

$15 / 24$

Bahia et al. 2017 are

monophyletic

2. Cestoplanidae appear monophyletic

3. Cestoplanidae appear within

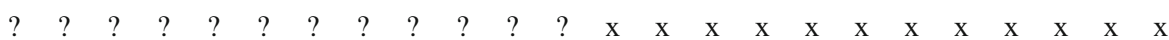
Cotylea

4. Cestoplanoidea is sister group to all other Cotylea

5. Pericelidae is monophyletic

6. Pericelidae is sister group to all Cotylea except Cestoplanoidea

7. Chromoplana and Anonymus recover as clade 1

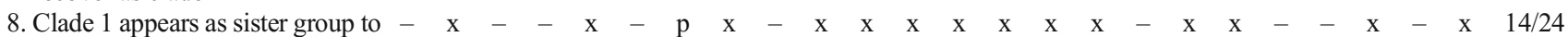
a clade including Prosthiostomoidea and Pseudocerotoidea

9. Pseudocerotoidea and

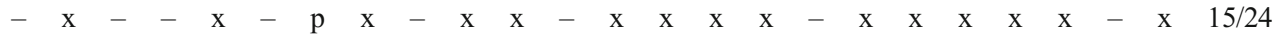
Pseudocerotidae sensu Bahia et al. 2017 are monophyletic

10. The species Pseudoceros, Pseudobiceros and Thysanozoon are not monophyletic

12. Euryleptidae sensu Faubel 1984 is split into two clades

12. Clade 2 is monophyletic

13. The clade still called

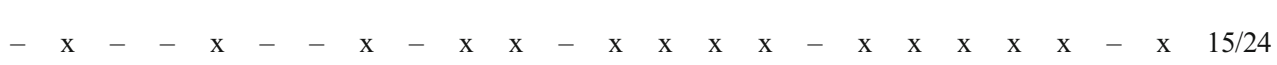

? ? ? ? ? ? ? ? ? ? ? ? ? ?

$----\mathrm{x}-{ }_{-}-\mathrm{x} \mathrm{x}-\mathrm{x}_{-\mathrm{x}}-\mathrm{x}_{-}-\mathrm{x}-\mathrm{x}_{-6 / 24}$

$\begin{array}{llllllllllllllllllllllllll}x & x & x & x & x & x & x & x & x & x & x & x & x & x & x & x & x & x & x & x & p & x & x & x & 23 / 24\end{array}$ Euryleptidae is recovered as paraphyletic

14. The genera Cycloporus and Prostheceraeus are recovered as monophyletic

15. Maritigrella is recovered as monophyletic

16. Prosthiostomoidea appears as monophyletic

17. Prosthiostomoidea is sister group to Pseudocerotoidea

18. Within Prosthiostomidae, Enchiridium appears as sister group to a clade consisting of Prosthiostomum, Lurymare and Amakusaplana

19. Prosthiostomum appears paraphyletic, as Amakusaplana and Lurymare cluster within

20. Chromoplanoidea (including Theama, Chromyella and Boninia) clusters within Cotylea

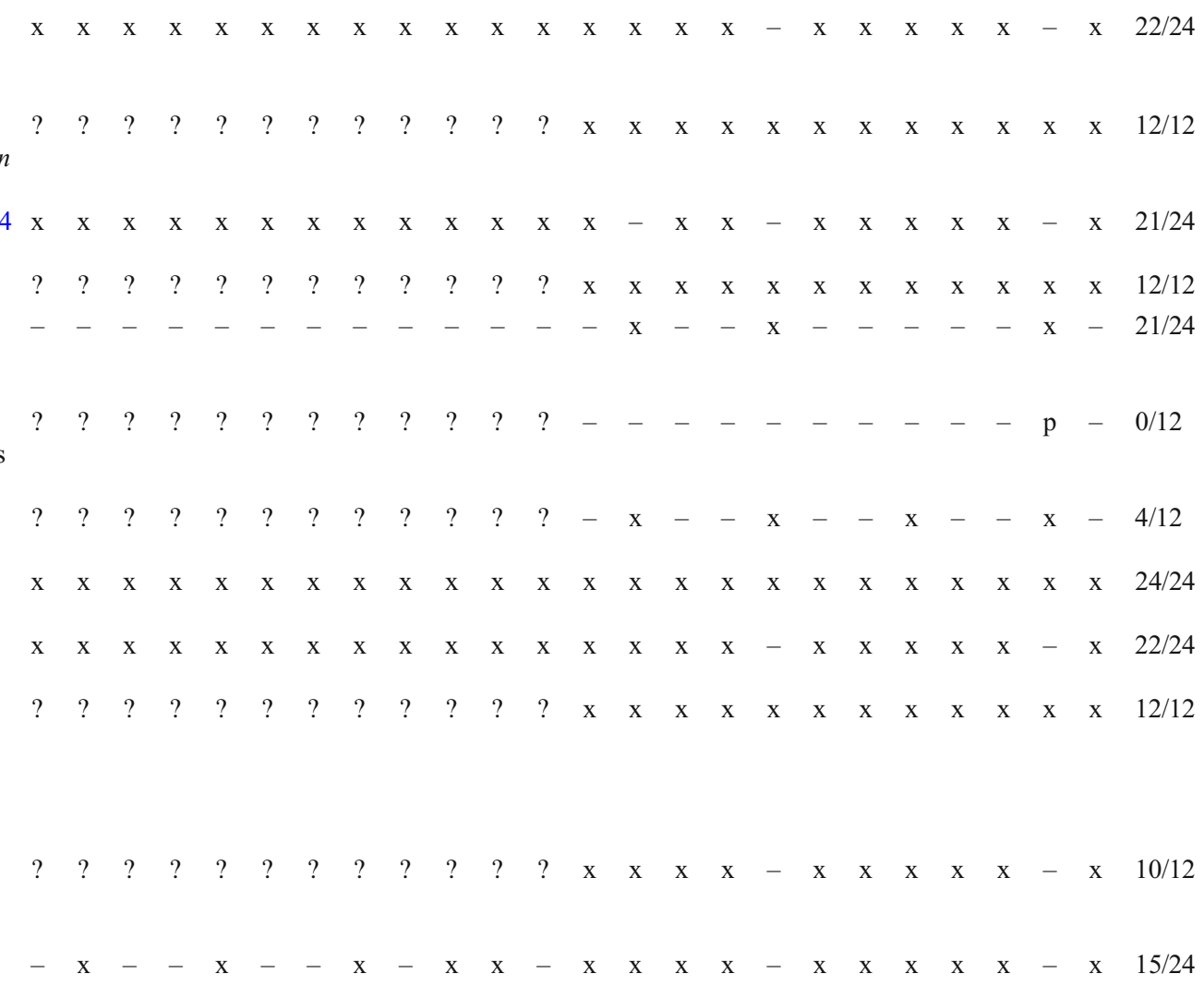


Table 2 (continued)

\begin{tabular}{|c|c|c|c|c|c|c|c|c|c|c|c|c|c|c|c|c|c|c|}
\hline \multirow[t]{5}{*}{ Suppl. Fig. S } & \multicolumn{10}{|c|}{ 18S28Slong } & \multicolumn{7}{|c|}{ 28Sshort6 } & \multirow[t]{3}{*}{ Support } \\
\hline & \multicolumn{5}{|l|}{ ML } & \multicolumn{5}{|l|}{ BI } & \multicolumn{4}{|l|}{$\mathrm{ML}$} & \multicolumn{3}{|l|}{ BI } & \\
\hline & \multicolumn{2}{|l|}{ GB } & \multicolumn{3}{|c|}{ No GB } & \multicolumn{3}{|c|}{ GB } & \multicolumn{2}{|c|}{ No GB } & \multicolumn{2}{|l|}{ GB } & \multicolumn{2}{|c|}{ No GB } & \multicolumn{2}{|l|}{ GB } & No GB & \\
\hline & $\mathrm{M} \mathrm{Q}$ & E & $\mathrm{M}$ & Q & $\mathrm{E}$ & M & Q & $\mathrm{E}$ & $M C$ & $\mathrm{E}$ & $M Q$ & $\mathrm{E}$ & $\mathrm{MC}$ & $\mathrm{Q} \quad \mathrm{E}$ & $\mathrm{M} \quad \mathrm{Q}$ & $\mathrm{E}$ & $M \quad \mathrm{E}$ & \\
\hline & 12 & 3 & 4 & 5 & 6 & 7 & 8 & 9 & 101 & 12 & 131 & 15 & 161 & $17 \quad 18$ & $19 \quad 20$ & 21 & $\begin{array}{lll}22 & 23 & 24\end{array}$ & \\
\hline
\end{tabular}

21. Chromoplanoidea as sister group to all other Cotylea, except Cestoplanoidea

$\begin{array}{lllllllllllllllllllllllllllllllll}\text { 22. Theamatidae is sister group to } & \mathrm{x} & \mathrm{x} & \mathrm{x} & \mathrm{x} & \mathrm{x} & \mathrm{x} & \mathrm{x} & \mathrm{x} & \mathrm{x} & \mathrm{x} & \mathrm{x} & \mathrm{x} & - & \mathrm{x} & - & \mathrm{x} & \mathrm{x} & \mathrm{x} & \mathrm{x} & \mathrm{x} & - & \mathrm{x} & \mathrm{x} & \mathrm{x} & 21 / 24\end{array}$ clade consisting of Boninia and

Chromyella

23. Leptoplanoidea sensu Faubel 1983 (in whose definition Hoploplana and Theama are included) is supported

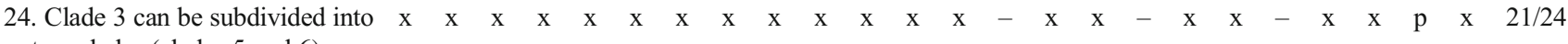
two clades (clades 5 and 6)

25. Clade 5 is synonymous with $\quad \begin{array}{rlllllllllllllllllllllllllllllllllll} & \mathrm{x} & \mathrm{x} & \mathrm{x} & \mathrm{x} & \mathrm{x} & \mathrm{x} & \mathrm{x} & \mathrm{x} & \mathrm{x} & \mathrm{x} & \mathrm{x} & \mathrm{x} & - & - & - & - & - & - & - & - & - & - & - & - & 12 / 24\end{array}$ Leptoplanoidea sensu Bahia et al. 2017

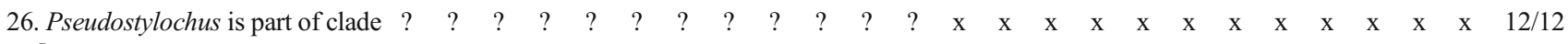
5

27. Leptoplana is monophyletic $\quad$ ?

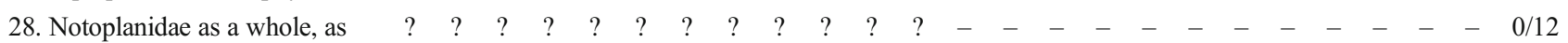
well as Notoplana are monophyletic, while

Notocomplana is not monophyletic

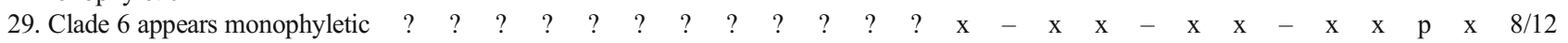

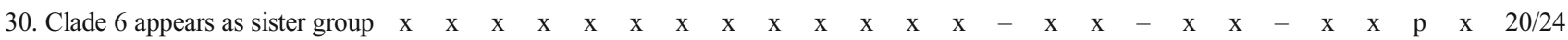
to clade 5

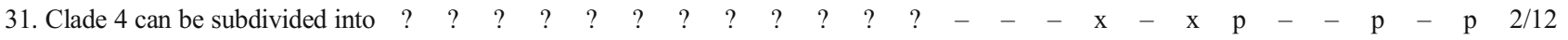
two clades, clades 7, 8 and

Callioplana, where the latter is sister group to clades $7+8$

32. A polytomy exists between Callioplana, clade 3 and clade 4

33. Clade 7 appears not monophyletic

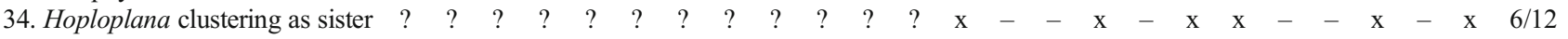
group to Idioplana, as clade 7

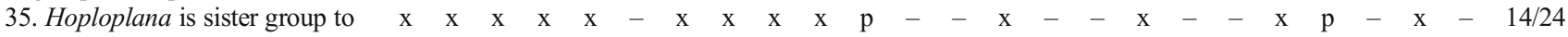
Planoceridae/Planocera pellucida

36. Clade 8 is monophyletic

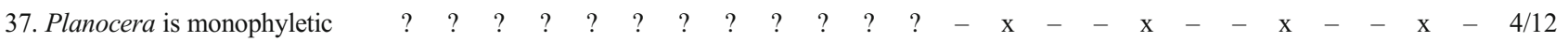

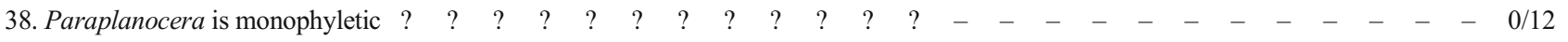

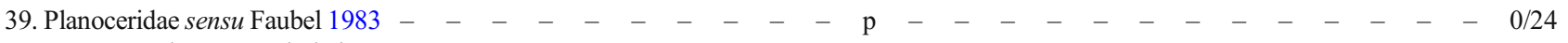
are recovered as monophyletic 40. Stylochus is monophyletic

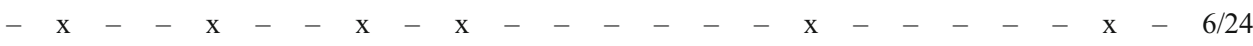
41. Imogine is monophyletic Total score ? ? ? ? ? ? ? ? ? ? ? ?

Total number of points possible

$\begin{array}{llllllllllllllllllllllll}17 & 21 & 17 & 17 & 20 & 15 & 17 & 21 & 17 & 20 & 18 & 16 & 34 & 32 & 34 & 33 & 23 & 33 & 32 & 29 & 30 & 32 & 21 & 32\end{array}$

22 (all lines except lines with ?)

38 (all lines except lines \#14, 33, and 34)

model choice, recovered a tree topology very different (Fig. 2b) from the one obtained with the 28Sshort1 alignment
(Fig. 2a) - again with Cycloporus variegatus as sister group to the remaining Polycladida (Fig. 2b). 
Now we also removed Chromoplana from the dataset (28Sshort4) and once more had C. variegatus as sister group to all other Polycladida. Also, Cestoplanoidea, Chromoplanoidea, Periceloidea and Anonymidae emerged as Acotylea (Fig. 4a). With the additional removal of C. variegatus from the sequence collection (28Sshort5), we recovered Cestoplanoidea, Chromoplanoidea, Periceloidea and Anonymidae as Cotylea once more - but only after alignment curation with Gblocks (Fig. 4b).

In a last change, we returned to the full dataset with updated sequences, but also used all available sequence variations for Cycloporus variegatus and Cycloporus gabriellae, instead of only using one sequence per species from the same authors (28Sshort6, Suppl. Figs. S13-24). We now recovered Cycloporus again within Cotylea, and present the detailed results using this dataset in the following section.

\section{Comparative tree topology using 28Sshort6 and 18S28Slong matrices}

All 12 trees using the 28Sshort6 matrix (Suppl. Figs. S13-24), and most of the 12 trees using the 18S28Slong matrix (Suppl. Figs. S1-12) are different from each other. We have analysed the tree topologies to identify stable and unstable taxa (Table 2). This table also gives an overview of which tree supports which topology. Additionally, we computed extended majority-rule consensus (MRE) trees from all 12 trees of the 18S28Slong matrix (Fig. 5), and all 12 trees of the 28Sshort6 matrix (Fig. 6). We also calculated separate 28Sshort6 and 18S28Slong matrix-based MREs for all alignments treated with or without Gblocks, respectively (Suppl. Figs. S25-28). If not otherwise stated, the MRE tree always refers to the MRE calculated from all twelve trees of each matrix. 'Trees' refers to both BI and ML trees, unless it is preceded by 'MRE'. Instead of citing all trees supporting a particular placement of a taxonomic group, we provide this information in Table 2 for better accessibility and overview.

In the following, we focus our comparisons on already defined families and superfamilies, mainly of the systems established by Faubel $(1983,1984)$ and Bahia et al. (2017).

The majority (63\%) of our trees, and the 28Sshort6 MRE tree support Cotylea and Acotylea sensu Bahia et al. (2017) and in the following we use these terms according to their definition: in brief, Theama and Cestoplana are cotyleans instead of acotyleans.

Cestoplanoidea (Bahia et al. 2017) and thereby its only family, Cestoplanidae, appear monophyletic in all our trees, even if its position within the trees differs widely. The majority $(63 \%)$ of our trees, and the 28Sshort6 MRE tree, support Cestoplanoidea within (and as sister group to all other) Cotylea, but in the remaining trees, it is sister group to Acotylea (33\%) or, in one case, polytomic.
Also $63 \%$ of our trees, and the 28Sshort6 MRE tree, support the phylogenetic position of Chromoplanoidea (Bahia et al. 2017, including Theama, Chromyella and Boninia) within Cotylea. Only $29 \%$ of our trees (all of them 28Sshort6 trees), as well as the $28 \mathrm{~S}$ short6 MRE tree, place Chromoplanoidea as sister group to all other Cotylea, except Cestoplanoidea. In $88 \%$ of our trees, and in both MRE trees, Theamatidae is sister group to a clade consisting of Boninia and Chromyella.

Periceloidea (Bahia et al. 2017) and thereby its only family, Pericelidae, is also monophyletic in all of our phylogenetic reconstructions and both MRE trees. They are most often either sister group to all Cotylea except Cestoplanoidea and Chromoplanoidea (25\% and the 28Sshort6 MRE tree), or sister group to Chromoplanoidea within Acotylea (25\% of all trees, but $100 \%$ of the 18 S28Slong Gblocks trees, and the 18S28Slong MRE tree). However, in 21\% of the trees, Periceloidea is placed as sister group to all Cotylea except Cestoplanoidea, or, also in $21 \%$ of the trees, Periceloidea is sister group to all Acotylea and Cestoplanoidea.

All but one of our trees, and both MRE trees recover Chromoplana and Anonymus as clade 1 and this clade mostly (58\% and both MRE trees) appears as sister group to a clade including Prosthiostomoidea (with the single family Prosthiostomidae) and Pseudocerotoidea (consisting of Pseudocerotidae, Euryleptidae and clade 2, see paragraph below).

Pseudocerotoidea and Pseudocerotidae sensu Bahia et al. 2017 are monophyletic in all but two trees, and in both MRE trees. Within Pseudocerotidae, all of our 28Sshort6 trees show that neither Pseudoceros, nor Pseudobiceros, nor Thysanozoon are monophyletic. The traditional family Euryleptidae sensu Faubel 1984 does not appear monophyletic in any of our trees, including the MRE trees. It is split into two clades (21 trees) or three clades ( 3 trees). In this work, we termed one of these clades 'clade 2' (while retaining the name Euryleptidae for the larger clade). The larger clade includes Cycloporus japonicus, Cycloporus variegatus, Prostheceraeus and Maritigrella in the 28Sshort6 trees, while Cycloporus is lacking in the 18S28Slong trees. Clade 2 consists of Euryleptodes galikias, Cycloporus gabriellae and Stylostomum ellipse in the 28Sshort6 trees, and only Stylostomum ellipse in the 18S28Slong trees. In the three trees, where the Euryleptidae sensu Faubel 1984 are split into three clades, even the clade still called Euryleptidae is recovered as paraphyletic. The genera Cycloporus and Prostheceraeus are never recovered as monophyletic in any of the 28Sshort6 trees, and also Maritigrella is only recovered as monophyletic in one third of the 28Sshort6 trees.

Prosthiostomoidea (Bahia et al. 2017) appears monophyletic in all trees, and in all but two trees as sister group to Pseudocerotoidea. Within Prosthiostomoidea, Enchiridium appears as sister group to a clade consisting of Prosthiostomum, Lurymare and Amakusaplana in all 

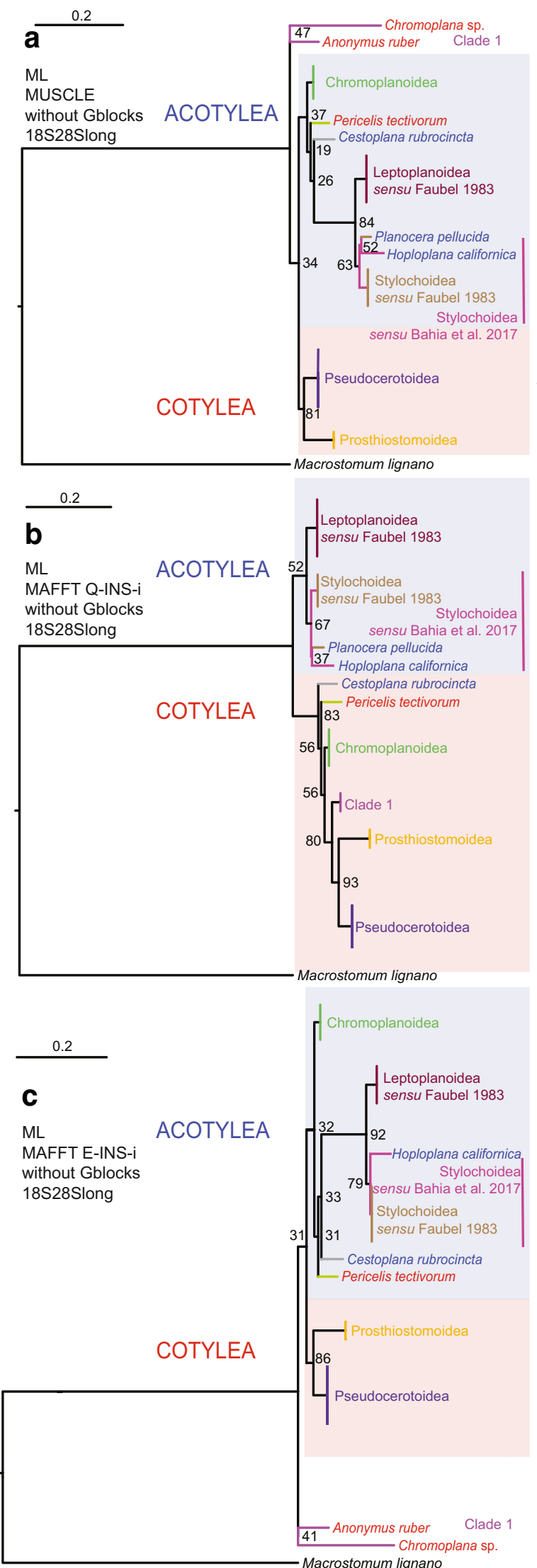
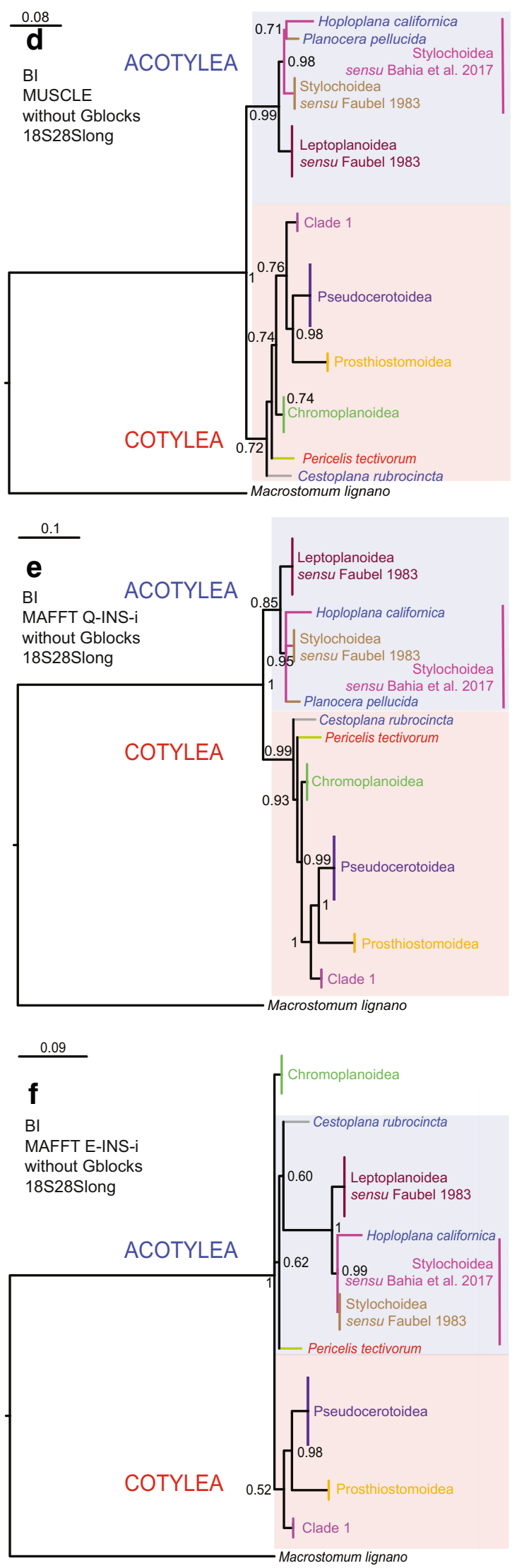
Fig. 1 Effect of model choice and alignment on tree topology. Tree reconstructions based on the $18 \mathrm{~S} 28$ Slong dataset, without using Gblocks. a-c Maximum likelihood. d-f Bayesian inference used for phylogenetic reconstructions. a, d MUSCLE alignments. b, e MAFFT Q-INS-i alignments. c, f MAFFT E-INS-i alignments. Node numbers indicate bootstrap support values $(\mathbf{a}-\mathbf{c})$ or posterior probabilities $(\mathbf{d}-\mathbf{f})$. Acotylea and Cotylea sensu Faubel 1983 and 1984 are written in blue and red fonts, respectively. Species recovered as Acotylea or Cotylea in our trees are displayed with blue and red background, respectively. Branches and nodes are given the same colour as their respective taxon

28Sshort6 trees. Prosthiostomum appears polyphyletic in $83 \%$ of our 28Sshort trees and also the 28Sshort MRE tree, as Amakusaplana and Lurymare cluster within.

Leptoplanoidea sensu Faubel 1983 (in whose definition Hoploplana and Theama are included) is not supported in any of our trees. We have termed Leptoplanoidea sensu Faubel 1983, but without Hoploplana and Theama, clade 3 (supported by all trees), which we further subdivided into two clades (clades 5 and 6).

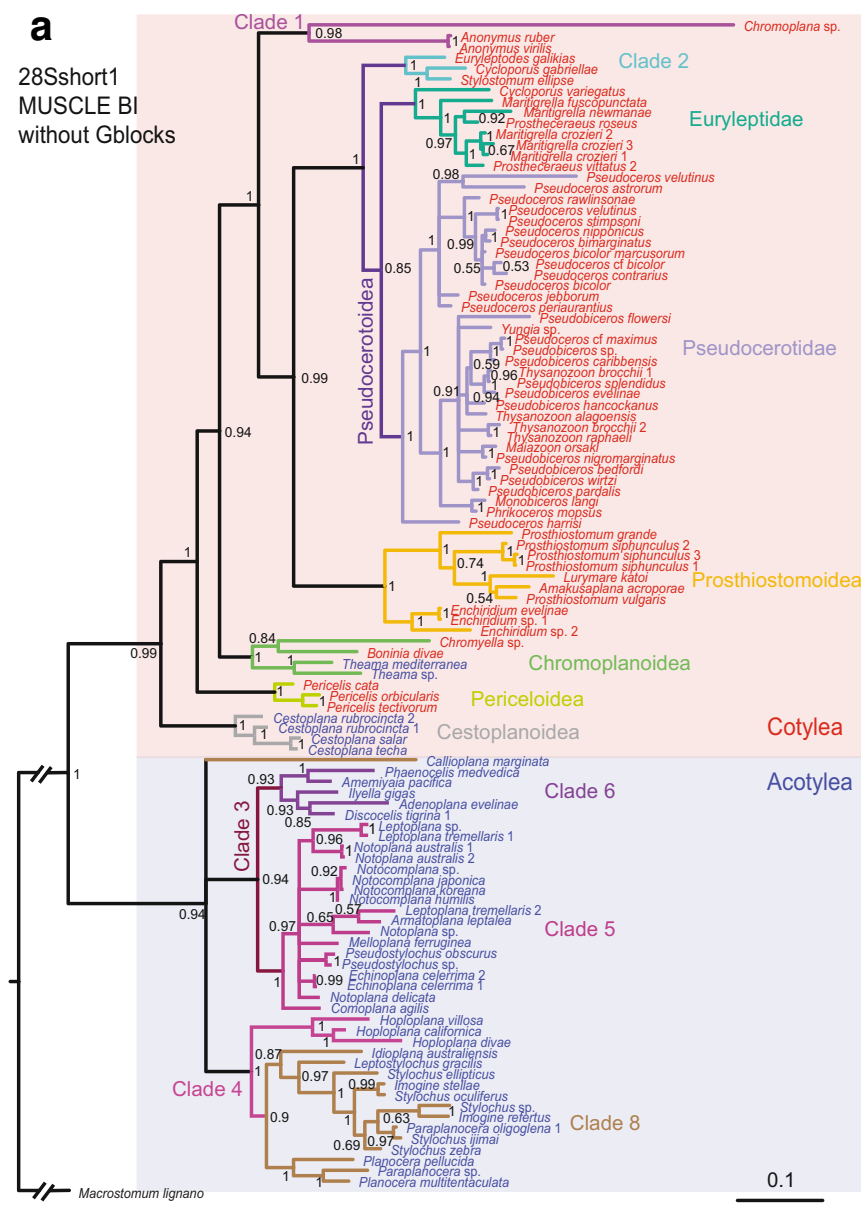

Fig. 2 Result of using versions 1 and 2 of sequences provided by Bahia et al. (2017). Bayesian inference tree reconstructions based on the 28Sshort1 (a) and 28Sshort3 (b) datasets, using MUSCLE alignments without Gblocks curation. The same taxa are used in (a) and (b), but with version 1 of sequences provided by Bahia et al. (2017) in (a) and version
In all $18 \mathrm{~S} 28$ Slong trees, clade 5 is synonymous with Leptoplanoidea sensu Bahia et al. (2017), as the genus Pseudostylochus is not available in these datasets. In all 28Sshort6 trees, Pseudostylochus is part of clade 5, but Pseudostylochus is not included in the superfamily's definition given by Bahia et al. (2017). All of our 28Sshort6 trees show that the genus Leptoplana is monophyletic, and that Notoplanidae as a whole and also its genera Notoplana and Notocomplana are not monophyletic.

In $58 \%$ of the 28 Sshort 6 trees and also the corresponding MRE tree, clade 6 is monophyletic, appears as sister group to clade 5 and includes Discocelis, Adenoplana, Ilyella, Phaenocelis and Amemiyaia. In our 18S28Slong trees and the corresponding MRE tree, clade 6 is represented only by Discocelis and always recovered as the sister group of clade 5.

Clade 4 can be subdivided into two clades, clades $7+8$ and their sister group Callioplana. This topology is supported by two of twelve 28Sshort6 trees, as well as the respective MRE tree, while in ten 28 Sshort6 trees, either a polytomy exists

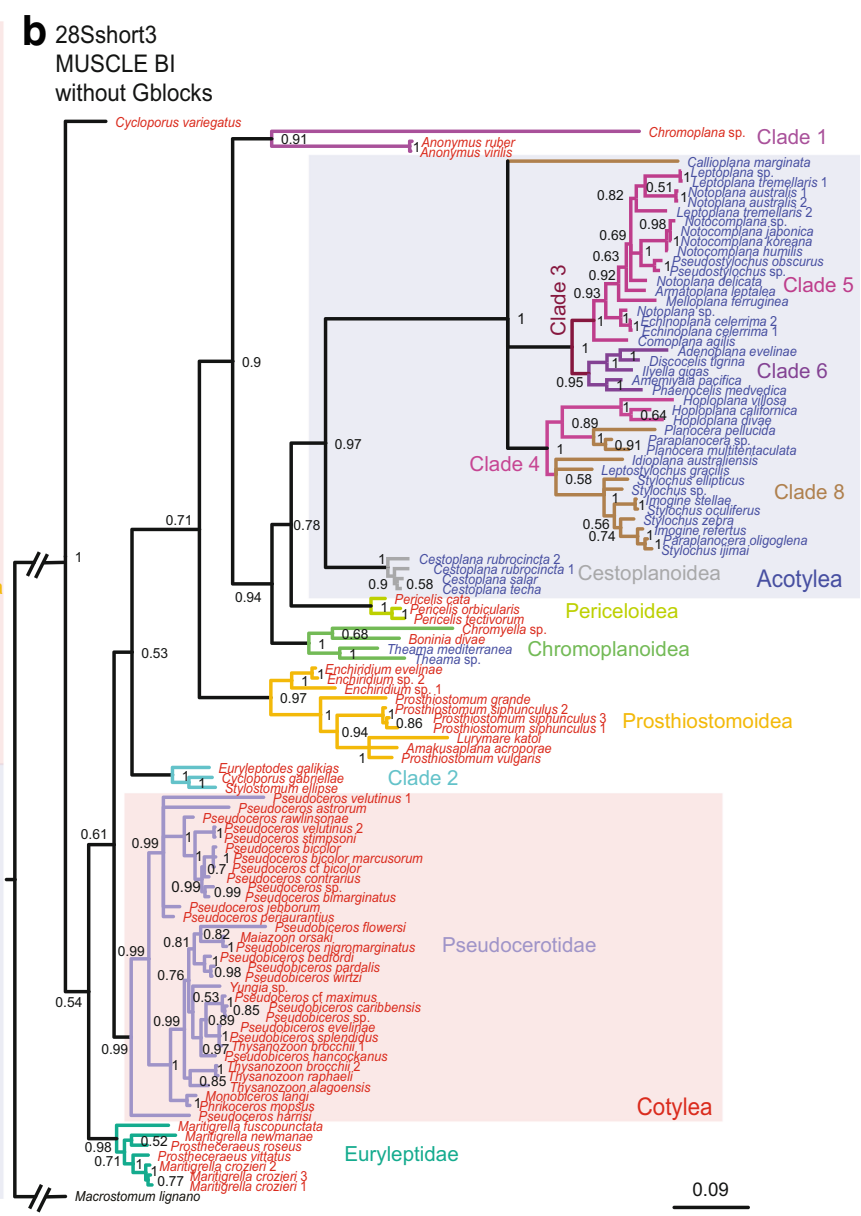

2 in (b). Node numbers indicate posterior probabilities. Acotylea and Cotylea sensu Faubel 1983 and 1984 are written in blue and red fonts, respectively. Species recovered as Acotylea or Cotylea in our trees are displayed with blue and red background, respectively. Branches and nodes are given the same colour as their respective taxon 


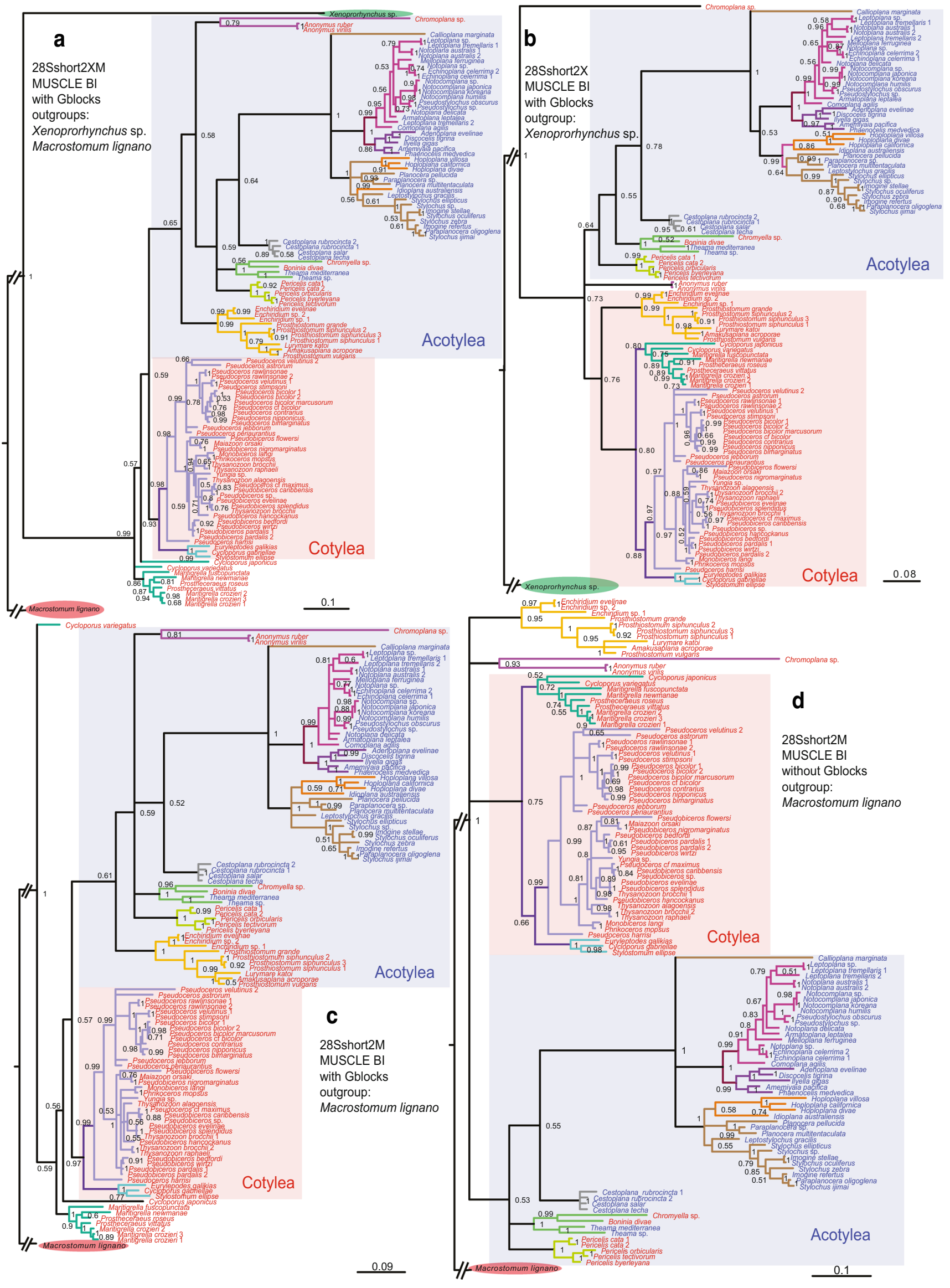


Fig. 3 Effect of outgroup selection and alignment curation on tree topology. a-d Bayesian inference tree reconstructions based on the 28Sshort2 datasets, using MUSCLE alignments with $(\mathbf{a}-\mathbf{c})$ and without (d) Gblocks. a 28Sshort2XM dataset including both Xenoprorhynchus sp. and Macrostomum lignano as outgroups. b 28Sshort2X dataset only including Xenoprorhynchus sp. as outgroup. c, d 28Sshort2M dataset only including Macrostomum lignano as outgroup. Node numbers indicate posterior probabilities. Acotylea and Cotylea sensu Faubel 1983 and 1984 are written in blue and red fonts, respectively. Species recovered as Acotylea or Cotylea in our trees are displayed with blue and red background, respectively. Branches and nodes are given the same colour as their respective taxon

between Callioplana, clade 3 and clades $7+8$, or clade 7 or 8 are not monophyletic, or several of these cases together.

In half of the 28Sshort6 trees, and also in the corresponding MRE tree, clade 7 is formed by Hoploplana clustering as sister group to Idioplana, but in one third of 28 Sshort6 trees, Hoploplana is sister group to Planoceridae in clade 8. In our 18S28Slong trees, clade 7 is only represented by Hoploplana californica, in nine of twelve trees (and also in the 18S28Sshort

a

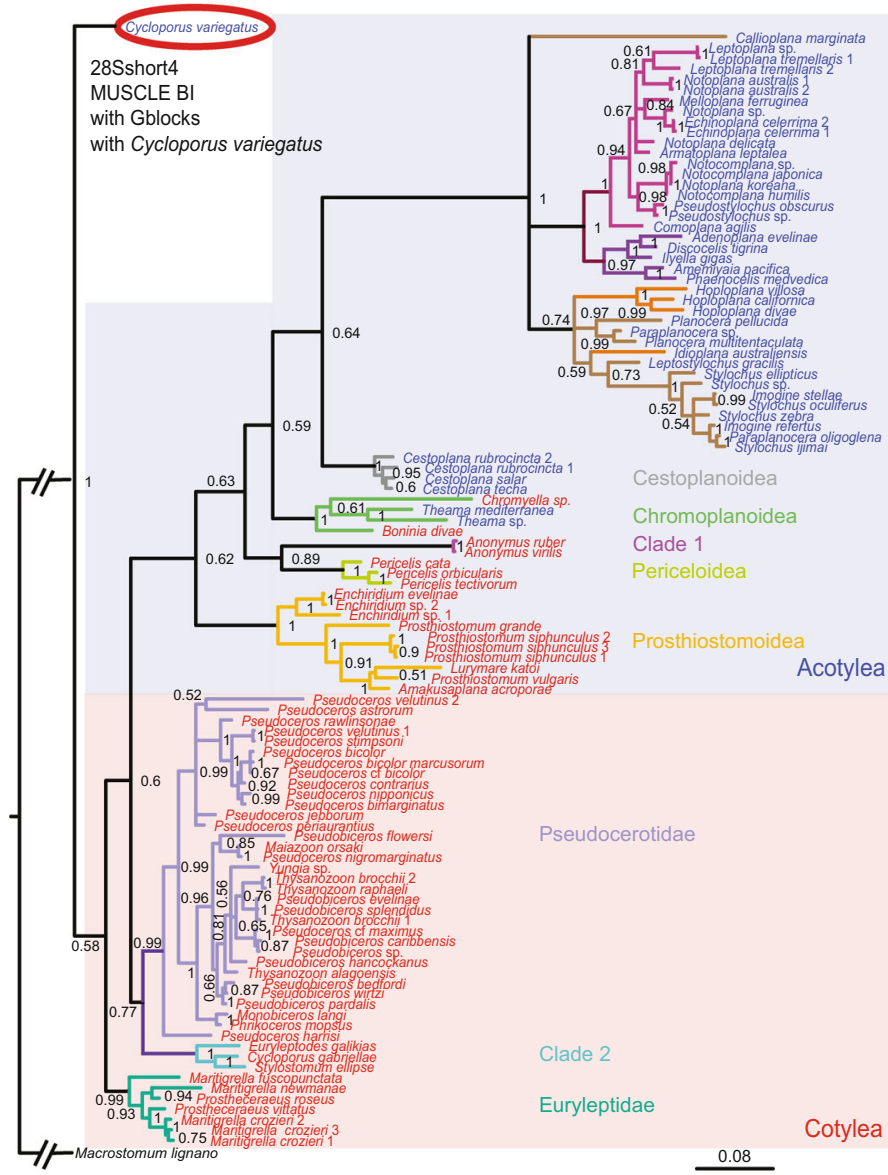

Fig. 4 Effect of taxon sampling on tree topology. a, b Bayesian inference tree reconstructions based on the 28Sshort4 dataset including Cycloporus variegatus (a) and the $28 \mathrm{Sshort5}$ dataset without Cycloporus variegatus (b), using MUSCLE alignments and Gblocks for alignment curation. Node numbers indicate posterior probabilities. Acotylea and Cotylea

MRE tree) as sister group to Planocera pellucida. In two cases, Planocera pellucida is clustering within clade 8 , while in one case, it is unresolved as a polytomy.

Clade 8 resembles Stylochoidea sensu Faubel (1983) and in the 28Sshort6 dataset, includes Leptostylochus, Stylochus, Imogine, Paraplanocera and Planocera, but excludes Faubel's Callioplana, Idioplana and Pseudostylochus. This clade is monophyletic in a minority (two of twelve) 28 Sshort6 trees and in the 28Sshort6 MRE tree. Clade 8 is polytomic in seven 28 Sshort 6 reconstructions and paraphyletic (including Idioplana and/or Hoploplana) in the remaining three 28 Sshort6 trees. In the 18S28Slong dataset, clade 8 is represented by Stylochus, Paraplanocera, Imogine and Planocera and thus conforming to Faubel's (1983) definition. Clade 8 is supported by only two of twelve of the 18S28Slong trees as well, but not in the 18S28Slong MRE tree, where Hoploplana is sister group to Planocera.

In $75 \%$ of our 28 Sshort 6 trees and also the corresponding MRE tree, Planocera is not monophyletic as Paraplanocera

b

28Sshort5 MUSCLE BI with Gblocks without Cycloporus variegatus
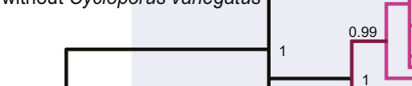

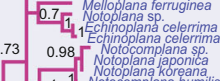

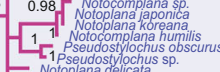
Clade 5

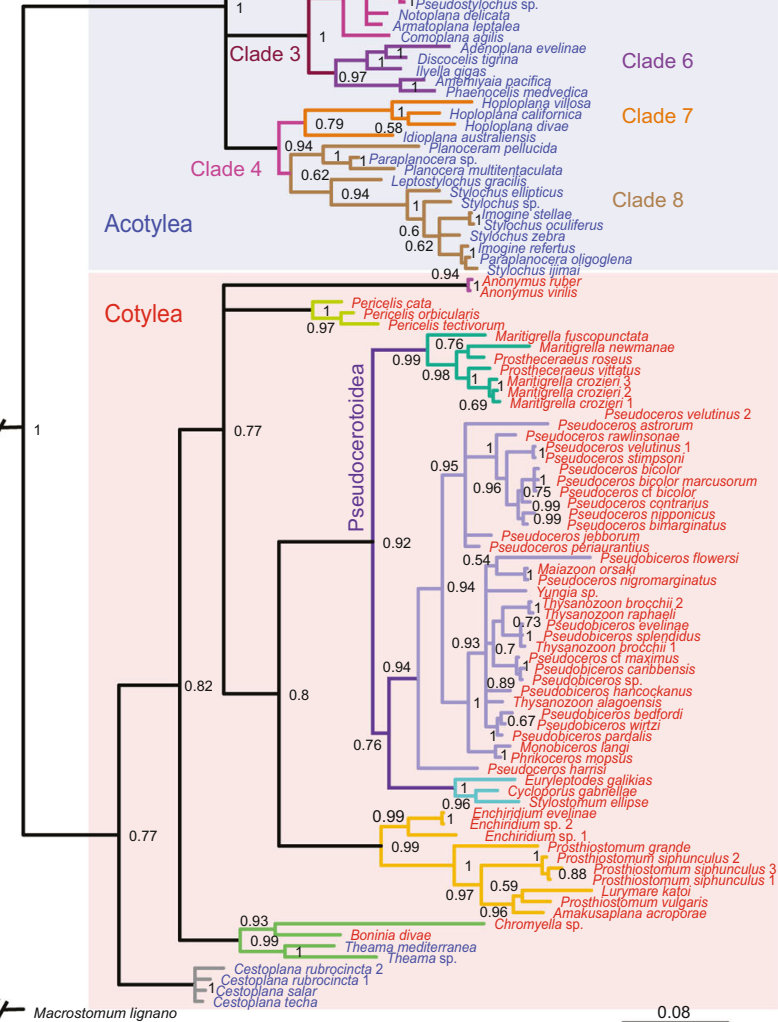

sensu Faubel 1983 and 1984 are written in blue and red fonts, respectively. Species recovered as Acotylea or Cotylea in our trees are displayed with blue and red background, respectively. Branches and nodes are given the same colour as their respective taxon 


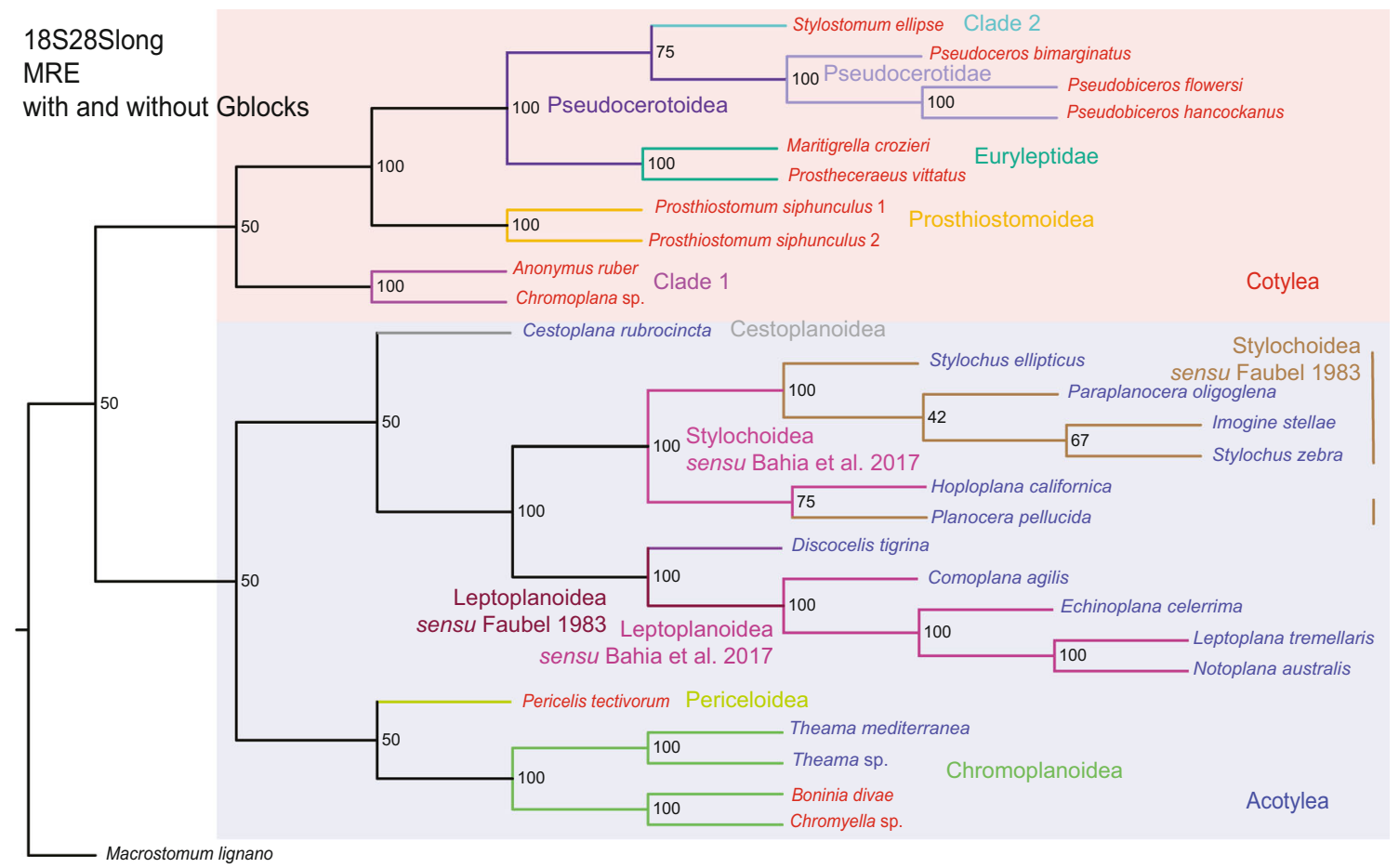

Fig. 5 Extended majority-rule consensus tree based on all 12 trees of the 18S28Slong dataset shown in Suppl. Figs. S1-12. Numbers indicate percentage of support. Acotylea and Cotylea sensu Faubel 1983 and 1984 are written in blue and red fonts, respectively. Species recovered as Acotylea

sp. clusters within. Similarly, Paraplanocera is not monophyletic in any of our 28Sshort6 trees, and Planoceridae sensu Faubel 1983 is not recovered as monophyletic in any tree. In the majority (75\%) of all trees, as well as in both MRE trees, the genus Stylochus is not monophyletic and in all 28Sshort6 trees, Imogine is not monophyletic.

\section{Discussion}

Taxon sampling and outgroup selection, as well as the choice of marker genes, the alignment method and the analysing statistical models affect the resulting phylogenetic reconstructions significantly (see e.g. Lockyer et al. 2003; Puslednik and Serb 2008; Aguado and Bleidorn 2010; Laumer and Giribet 2017). For polyclad interrelationships using mainly a rather short stretch of the 28S rDNA marker gene, but also a longer sequence comprised of both partial $18 \mathrm{~S}$ and $28 \mathrm{~S}$ rDNA, we show that the change of any of these parameters can vastly change the resulting tree topology (Figs. 1, 2, 3 and 4). A strong hypothesis about valid polyclad interrelationships is thus challenging, and we have therefore used majority-rule consensus trees to help us decide between different topologies (Figs. 5 and 6) and also manually analysed the support of different hypotheses (Table 2). To our knowledge, this is the first time that these difficulties and inconsistencies are discussed or even mentioned in regard to polyclad interrelationships. or Cotylea in our trees are displayed with blue and red background, respectively. Branches and nodes are given the same colour as their respective taxon

\section{Alignment is important}

MUSCLE (Edgar 2004) was the alignment method of choice in both recently published polyclad phylogenies based on partial 28S sequences (Bahia et al. 2017; Tsunashima et al. 2017), and was also used in one of the best-scoring trees in both datasets shown here (Table 2, Suppl. Figs. S10, 13). We have also used two different variants of MAFFT (Katoh and Standley 2013); previously, MAFFT E-INS-i was selected for the polyclad phylogeny based on mitochondrial sequences (Aguado et al. 2017) and for an all-flatworm phylogeny working with the nearly complete nuclear ribosomal marker genes, $18 \mathrm{~S}$ and $28 \mathrm{~S}$ (Laumer and Giribet 2017). The other best-scoring 28Sshort6 tree according to our scoring in Table 2 is MAFFT E-INS-i aligned (Suppl. Figs. S15), and another MAFFT E-INS-i tree (Suppl. Fig. S18) is also closest to the topology shown in the MRE 28Sshort6 tree (Fig. 6). MAFFT Q-INS-i is by far the most computationally demanding alignment method, and was also employed quite extensively for resolving flatworm interrelationships on the level of orders based on partial $18 \mathrm{~S}$ and $28 \mathrm{~S}$, e.g. macrostomorphs (Janssen et al. 2015), rhabdocoels (van Steenkiste et al. 2013; Tessens et al. 2014) and proseriates (Casu et al. 2014; Scarpa et al. 2015, 2016, 2017). The two best-scoring 18S28Slong trees are both based on a MAFFT Q-INS-i alignment (Table 2, Suppl. Figs. S2, 8).

However, the two worst-scoring 28Sshort6 trees are also based on MAFFT Q-INS-i alignments (Table 2, Suppl. Figs. 


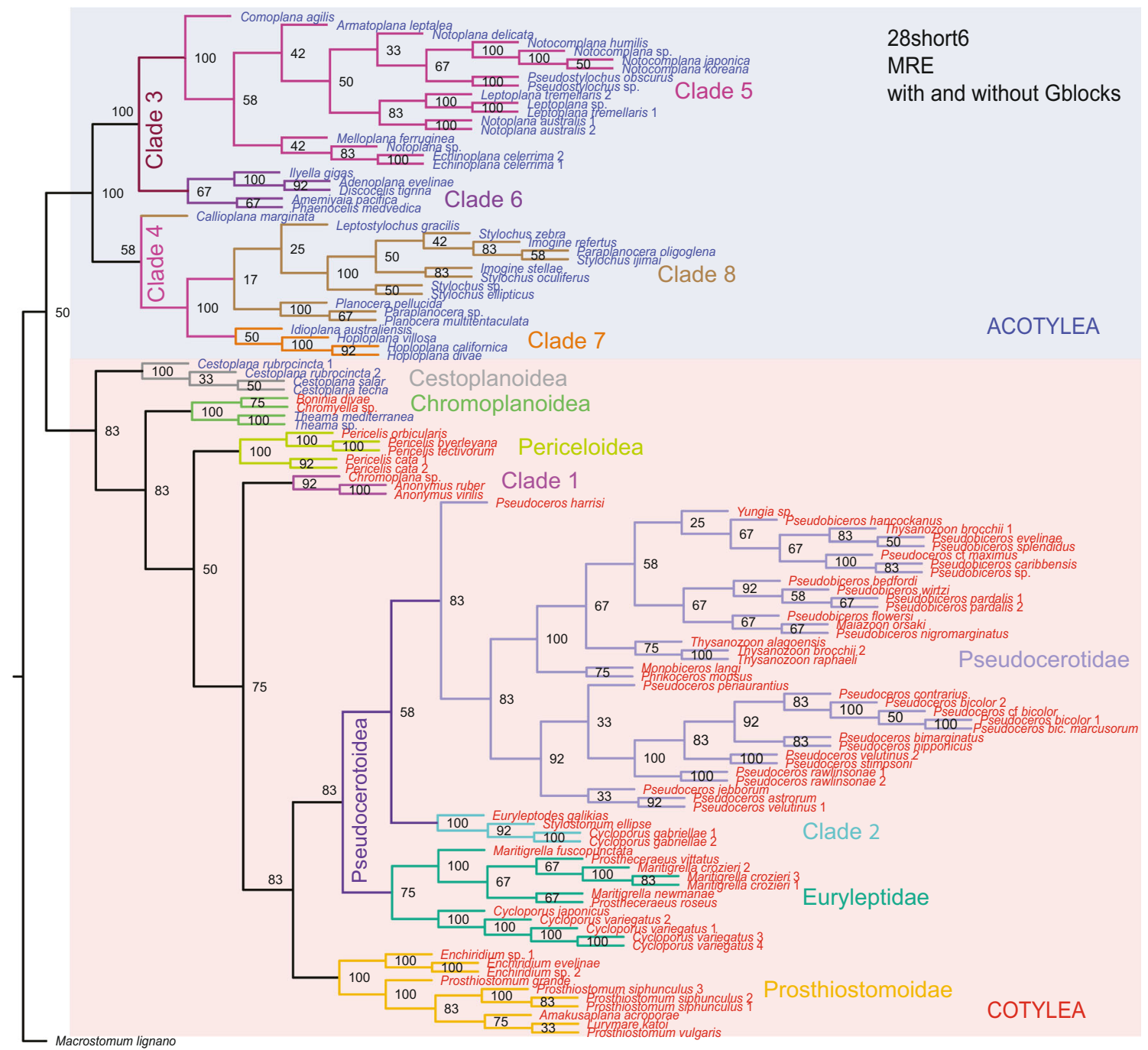

Fig. 6 Extended majority-rule consensus tree based on all 12 trees of the 28Sshort6 dataset shown in Suppl. Figs. S13-24. Numbers indicate percentage of support. Acotylea and Cotylea sensu Faubel 1983 and 1984 are written in blue and red fonts, respectively. Species recovered as Acotylea or Cotylea in our trees are displayed with blue and red background, respectively. Branches and nodes are given the same colour as their respective taxon
S17, 23), while the two worst-scoring 18S28Slong trees are MAFFT E-INS-i aligned (Table 2, Suppl. Figs. S6, 12).

The tree topologies resulting from these widely used alignment methods are not consistent (Fig. 1, Suppl. Figs. S1-24), corroborating the findings of Laumer and Giribet (2017), in which they reanalysed their differently aligned dataset from their earlier publication (Laumer and Giribet 2014) and also recovered trees with several major differences. In their re-analysis, they used MAFFT E-INS-i instead of RNAsalsa (Stocsits et al. 2009), and then recovered a tree very similar to two independently made transcriptomic analyses of flatworm interrelationships (Egger et al. 2015, Laumer et al. 2015), suggesting that MAFFT E-INSi provided a more robust alignment than RNAsalsa.

From this work, we cannot give an unambigious recommendation for the most suitable alignment method, but recommend to use at least two different methods to check for consistency.

\section{Model choice is important}

In the work presented here, we consistently recovered inconsistent BI and ML topologies using the same datasets and alignments (Table 2, Fig. 1). In the most recently published polyclad phylogeny, both BI and ML trees gave congruent results (Litvaitis et al. 2019). In other recent polyclad phylogenies based on partial 28S, only either BI (Rawlinson and Stella 2012) or ML (Bahia et al. 2017, Tsunashima et al. 2017) were used, so no comparisons between different models can be made. In two polyclad phylogenies, both BI and ML analyses were run, and the trees show the same 
topology in Rawlinson et al. (2011) and are 'highly congruent' in a mitochondrial gene analysis with several switches within families, but not of the overall topology (Aguado et al. 2017). Both models were used to resolve interrelationships within other flatworm orders, and reported with very similar or identical results using combined $18 \mathrm{~S}$ and $28 \mathrm{~S}$ datasets (Casu et al. 2014; Tessens et al. 2014; Janssen et al. 2015; Scarpa et al. 2015, 2016, 2017), in one case also including mitochondrial markers (Janssen et al. 2015). While these studies usually use a matrix of more than $3000 \mathrm{nt}$, our own large matrix with more than $3000 \mathrm{nt}$ positions gives less congruent results among different models and alignments than our short matrix (ca. $800 \mathrm{nt}$ ) (Table 2, Figs. 5 and 6), indicating that taxon sampling may be even more important than matrix length.

Again, we recommend to use both models (BI and ML) to check for consistency between the models. In our case, results were not consistent, indicating that taxon sampling and matrix length were not sufficient yet.

\section{Outgroup selection is important}

We have tested the influence of outgroup choice on tree topology with Macrostomum lignano, a basally branching rhabditophoran, and Xenoprorhynchus sp., a basally branching prorhynchid-Prorhynchida being sister group of Polycladida (Egger et al. 2015, Laumer et al. 2015), using the same alignment (MUSCLE) and alignment curation (Gblocks), as well as the same model (BI) and the same dataset (28Sshort2). We found markedly different tree topologies between using both Macrostomum and Xenoprorhynchus, only Xenoprorhynchus or only Macrostomum as ougroups (Fig. 3a-c). Especially the sister group relationships of either Chromoplana sp. or Cycloporus variegatus with all other polyclads (Fig. 3b, c) were the reason to also test the influence of taxon sampling on the polyclad tree topology (Fig. 4).

An almost identical dataset, aligned with the same algorithm and tree reconstruction done with the same model and by the same leading author yielded two different topologies: in the first account, both Cestoplana and Pericelis are basally branching Acotylea (Rawlinson et al. 2011), while these two taxa switch to basally branching Cotylea in the second account (Rawlinson and Stella 2012). The only two differences in the reconstructions are one instead of two outgroups and a third sequence of Amakusaplana acroporae in the second paper (Rawlinson and Stella 2012), indicating that a higher number of outgroups gives more reliable results in their case. In our own datasets, we found no clear preference for outgroup selection (Fig. 3), making us default on a single, basally branching outgroup (Macrostomum lignano) for our main datasets (28Sshort6 and 18S28Slong).

\section{Taxon sampling is important}

Not only the long-branching Chromoplana (therefore excluded from the analysis in Bahia et al. 2017), but also Cycloporus variegatus was prone to upend the tree topology in the 28S trees (Figs. 3b, c and 4). Interestingly, both the complete removal of Chromoplana and all Cycloporus sequences, and the addition of more variants of Cycloporus species yielded similar tree topologies (Figs. $4 \mathrm{~b}$ and 6 ). We have not tested removing taxa from the 18S28Slong dataset, but at least in theory, it should be more robust to taxon sampling artefacts than the much shorter 28Sshort dataset. In general, and as stated above, taxon sampling seems to be more important for resolving a stable polyclad phylogeny than matrix length at this point.

\section{Correct determination is important}

The correct identification of species is far-reaching for the interpretation of phylogenetic trees. During our analysis, we realised several inconsistencies in species determination of so far published sequences. In several of our 28 Sshort6 trees, as well as in the corresponding MRE (Fig. 6), a sequence tagged as Paraplanocera sp. (KY263699.2) on GenBank clusters within Planocera. Therefore, Planocera does not appear monophyletic (Table 2, Fig. 6). However, according to Bahia et al. (2017), this sequence and the associated accession number belongs to Planocera sp.; hence, Planocera would be monophyletic also in our trees. We found several similar problems with sequences listed as 'Leptoplana sp. or Notoplana sp.' in Table 1 of Bahia et al. (2017). In their table, these sequences have the accession numbers KY263695, KY263650, KY262696, KY263698 and KY263651. KY262696 is apparently a typo and should read KY263696, which together with KY263695 and KY263698 is tagged as 'Leptoplana tremellaris' on GenBank, while KY263650 and KY263651 are labelled as 'Notoplana sp.' on GenBank. In their tree, Bahia et al. (2017) also show an unlisted Notocomplana sp., but it is not clear to which accession number this species refers to. As usual, we only took one sequence of the same species from the same authors, and we have used KY263695 (Leptoplana tremellaris) and KY263650 (Notoplana sp.) in our phylogenetic reconstructions (Table 1). Interestingly, in our 28Sshort6 MRE tree (Fig. 6), this Notoplana sp. by Bahia et al. (2017) does not cluster with any other Notoplana, Notocomplana (Notoplanidae) or Leptoplana (Leptoplanidae) species, but with Melloplana (Pleioplanidae) and Echinoplana (Gnesiocerotidae).

Also Pseudoceros is not monophyletic in our analyses, as two species, Pseudoceros harrisi and Pseudoceros cf. maximus are clustering outside the other 13 included Pseudoceros species (Fig. 6). Pseudoceros harrisi is consistently recovered as sister group to all other Pseudocerotidae in 
our trees and also by Bahia et al. (2017) and Tsunashima et al. (2017). In its species description, which is based on a single damaged specimen, it is stated that 'This species does not resemble any other species of Pseudoceros. However, P. harrisi may be confused with members of Cycloporus [...]' (Bolaños et al. 2007). Hence, the phylogenetic position of Pseudoceros harrisi might be the result of a misdetermination of its genus in the original description. The Pseudoceros cf maximus sequence (KY263708) we used was published by Bahia et al. (2017) and it appears with high support within Pseudobiceros in our reconstructions (Fig. 6). We noticed that the species name Pseudoceros cf maximus does not appear in Bahia et al.'s tree. On the other hand, they show two branches labelled 'Pseudobiceros spp.' in their tree, but only list a single Pseudobiceros sp. sequence in their Table 1. Taking into account our own results, we believe it is possible that the sequence published as Pseudoceros cf maximus on GenBank is one of the 'Pseudobiceros sp.' in their tree.

Several sequences have undergone name changes after redetermination efforts by the authors, or have dubious affiliations. For example, Cestoplana rubrocincta from Australia (C. rubrocincta 2 in our tree, HQ659009.1) is labelled as C. australis in the tree provided by Rawlinson et al. (2011), but called C. rubrocincta in their table, and also on GenBank. Other sequence names were updated without changing their accession number versions. We originally downloaded the following sequences published in Tsunashima et al. (2017) from GenBank in June 2017, but they were subsequently renamed: Discoplana sp. to Ilyella gigas (LC100080), Notoplana koreana to Notocomplana koreana (LC100086), Melloplana japonica to Notocomplana japonica (LC100087), Cycloporus sp. to Cycloporus japonicus (LC100092), Thysanozoon sp. 1 to Thysanozoon brocchii (LC100093), Thysanozoon sp. 2 to Thysanozoon japonicum (LC100094), Pseudoceros sp. 1 to Pseudoceros velutinus (LC100095), Pseudoceros sp. 2 to Pseudoceros nipponicus (LC100096), and Pseudoceros sp. 3 to Pseudobiceros nigromarginatus (LC100097).

\section{Sequence problems}

When we started with this study in 2017 , we noticed gaps in all newly generated sequences uploaded to GenBank by Bahia et al. (2017). The first set of 28Sshort trees we made was based on a dataset including these sequences. We later realised that the gaps in the sequences were caused by alignment curation using Gblocks (J. Bahia, pers. comm.), and all other trees (using the 28Sshort2-6 sequence collections) were based on the updated sequences (version 2 on GenBank). We provided reconstructions based on both, Gblocks curated and original alignments, and often recovered different topologies if all other parameters stayed the same (Table 2, Fig. 3). According to a recent publication, phylogeny may be even better without using Gblocks or similar alignment curation programs (Tan et al. 2015). In our own study, however, we find that the bestscoring trees were made with datasets using Gblocks for alignment curation (Table 2).

Some of the sequences published by Tsunashima et al. (2017) appear to be quite different to all other polyclad sequences published, especially in the $5^{\prime}$ region: among these are the above-mentioned Cycloporus japonicus (LC100092), Thysanozoon brocchii (LC100093) and Thysanozoon japonicum (LC100094). We initially removed all of these sequences from further analyses, but later added Cycloporus japonicus (28Sshort2 and 28Sshort6) despite the divergent sequence. Also Chromoplana sp. from Laumer and Giribet (2014) was an unusual sequence and was therefore removed from the tree of Bahia et al. (2017), but is included in most of our reconstructions (except 28Sshort4-5).

Although termed as 'clones' on GenBank, there is a considerable difference between the four published Cycloporus variegatus sequences by Bahia et al. (2017); we believe these sequences are not derived from clones, but from different specimens of the same species.

Polyclad phylogenies based on partial 28S rDNA published by different authors used different primers, making the integration of all sequences a challenge, as the overlapping regions get smaller. Especially Tsunashima et al. (2017) used a region of the $28 \mathrm{~S}$ gene more towards the $3^{\prime}$ end than all other studies, but we have still included most of their sequences, because they provide important taxa not covered by our own or other previously published sequences. For future studies, we recommend amplifying $28 \mathrm{~S}$ starting with expansion segment D1 and stretching as long as possible, to maximise compatibility with published sequences.

\section{Classification on suborder and superfamily level}

On suborder level, our 28Sshort6 trees are mostly compatible with the molecular phylogenetic hypothesis of Bahia et al. (2017), supporting their redefinition of Cotylea and Acotylea (see Table 2 and Fig. 6). There, two traditional actoylean families, Cestoplanidae and Theamatidae, switched from Acotylea to Cotylea.

The majority of the 18S28Slong trees, on the other hand, support Cestoplanidae and Theamatidae as acotyleans. Also, the traditionally cotylean genera Pericelis, Boninia and Chromyella are recovered as acotyleans (Table 2, Fig. 5). In this scenario, a sucker would be a character at the base of Polycladida and would have been lost at least five times: in the traditional Acotylea, in some Cestoplanidae, in the anonymid Simpliciplana marginata (Kaburaki 1923), in Theamatidae, in Amakusaplana (Rawlinson et al. 2011), and possibly in Chromyella (Fig. 5 and Faubel 1983, 1984, Prudhoe 1985). In the 28Sshort6 scenario, a sucker would 
be present at the base of Cotylea and would have been lost one time less, i.e. not in Acotylea (Fig. 6). According to Bahia et al. (2017), a 'true sucker' may have gradually evolved and may be an apomorphy of Prosthiostomoidea and Pseudocerotoidea. A true sucker is muscular and characterised by a modified epithelium with a thin basement membrane, while the adhesive disc or pad found in Boninia and Cestoplana is just a shallow depression of the epithelium not differentiated from the parenchyma (Prudhoe 1985; Rawlinson and Litvaitis 2008). Both true sucker and adhesive disc/pad are always located posterior of the genital openings. Several Pericelis species (excluded from having a true sucker in Bahia et al. 2017, but listed as having a true sucker in Rawlinson and Litvaitis 2008) are described with a 'distinct sucker' (Dittmann et al. 2019), so we suggest that the true sucker behind the genital openings already is an apomorphy for the unnamed group including Periceloidea, Anonymus, Chromoplana, Prosthiostomoidea and Pseudocerotoidea (Fig. 6). The acotylean genus Leptoplana has a sucker (a socalled genital pit) between the genital openings (Prudhoe 1985); therefore, it is excluded from the definition of a cotylean sucker.

Based on this scenario of sucker evolution in polyclads, it is more parsimonious to support the 28Sshort6 tree topology, although the 18S28Slong alignment with ca. $3000 \mathrm{nt}$ is almost four times as long as the 28Sshort6 alignment with ca. $900 \mathrm{nt}$. Also, the support values of the trees rejecting Cotylea and Acotylea sensu Bahia et al. (2017) are consistently lower than those supporting them (Suppl. Figs. S1-24). In five of the twelve 18S28Slong trees, Cotylea and Acotylea sensu Bahia et al. (2017) are actually supported, and also in the 18S28Slong MRE tree without Gblocks (Suppl. Fig. S26). Only the 18S28Slong dataset using Gblocks skews the picture towards a weakly supported topology making Cestoplanidae, Theamatidae, Pericelis, Boninia and Chromyella acotyleans (Suppl. Fig. S25), also in the combined 18S28Slong MRE tree (Fig. 5).

In all but two 28 Sshort6 trees, Cotylea and Acotylea sensu Bahia et al. (2017) are well supported (Fig. 6, Suppl. Figs. S13-16, 18-22, 24). On the other hand, we have shown that this topology is very much dependant on taxon sampling, outgroup selection, alignment method and curation, and model choice (Figs. 1, 2, 3 and 4). Possibly, the most important parameter is taxon sampling, and this would explain why a much larger alignment (18S28Slong) with 27 polyclad terminals and 26 different polyclad species gives less consistent results than the shorter matrix (28Short6) with 118 polyclad terminals and 100 different polyclad species. Bahia et al. (2017) show 136 polyclad terminals, but only 55 different polyclad species, and Tsunashima et al. (2017) use 53 polyclad terminals and 50 polyclad species in their phylogenetic trees. While we have not tested their original datasets with different parameters here, their results suggest that neither the number of taxa, nor sequences are decisive for tree topology, but that some sequences are prone to change tree topology, among them Chromoplana, Cycloporus variegatus and Cycloporus japonicus (Figs. 3 and 4). As long as single taxa included or excluded can drastically change tree topology even in the overall more consistent 28S-only trees, polyclad phylogeny remains only preliminarily resolved, calling for larger datasets like in transcriptomic phylogenies.

However, apart from the position of Cestoplanidae, Theamatidae, Pericelis, Boninia, Chromyella, Anonymidae and Chromoplana in the tree, we find that most polyclad taxa are included in very well-supported clades.

Our data support the following new superfamilies sensu Bahia et al. (2017):

Pseudocerotoidea sensu Bahia et al. (2017); this superfamily includes Pseudocerotidae and two clades of Euryleptidae in their reconstruction. In this work, we termed one of these clades 'clade 2' as all relevant trees show this non-monophyly (Table 2). This division can also be observed in the study of Bahia et al. (2017), where Cycloporus gabriellae represents our clade 2 of Euryleptidae, while Cycloporus variegatus and Cycloporus japonicus are part of the remaining Euryleptidae. Also in a cladistic analysis, Euryleptidae was not recovered as monophyletic (Rawlinson and Litvaitis 2008). As already suggested before, the genus Cycloporus needs to be revised, but no obvious characters to distinguish between described Cycloporus species could be determined so far (Bahia et al. 2017). Our data show that the separation of the Cycloporus species not only results from potential inconsistencies within the genus Cycloporus, as also Stylostomum and Euryleptodes appear within clade 2 . Therefore, we propose the revision of the whole family of Euryleptidae. As Eurylepta has been shown to cluster as sister group of other Euryleptidae in a phylogeny based on mitochondrial genes (Aguado et al. 2017), the family name Euryleptidae should be retained for the group containing Maritigrella, Prostheceraeus, Cycloporus variegatus and Cycloporus japonicus (Fig. 7). Cycloporus japonicus has been shown to group with Maritigrella in Tsunashima et al. (2017) as well. We propose the new family name Stylostomidae fam. nov. for clade 2, including at least Stylostomum, Euryleptodes and Cycloporus gabriellae. In the recently published work by Litvaitis et al. (2019), both Euryleptidae and Cycloporus appear as monophyletic, but neither Stylostomum, nor Euryleptodes are included in their study. As in our study, Litvaitis et al. (2019) have recovered both, Prostheceraeus and Maritigrella, as non-monophyletic and consequently they have synonymised Maritigrella as junior synonym with Prostheceraeus.

Pseudoceros, Pseudobiceros and Thysanozoon are not recovered as monophyletic in our study, agreeing with Bahia et al. (2017) and Tsunashima et al. (2017), stressing the need of further revision of the family Pseudocerotidae (Litvaitis and Newman 2001; Rawlinson and Litvaitis 2008). 


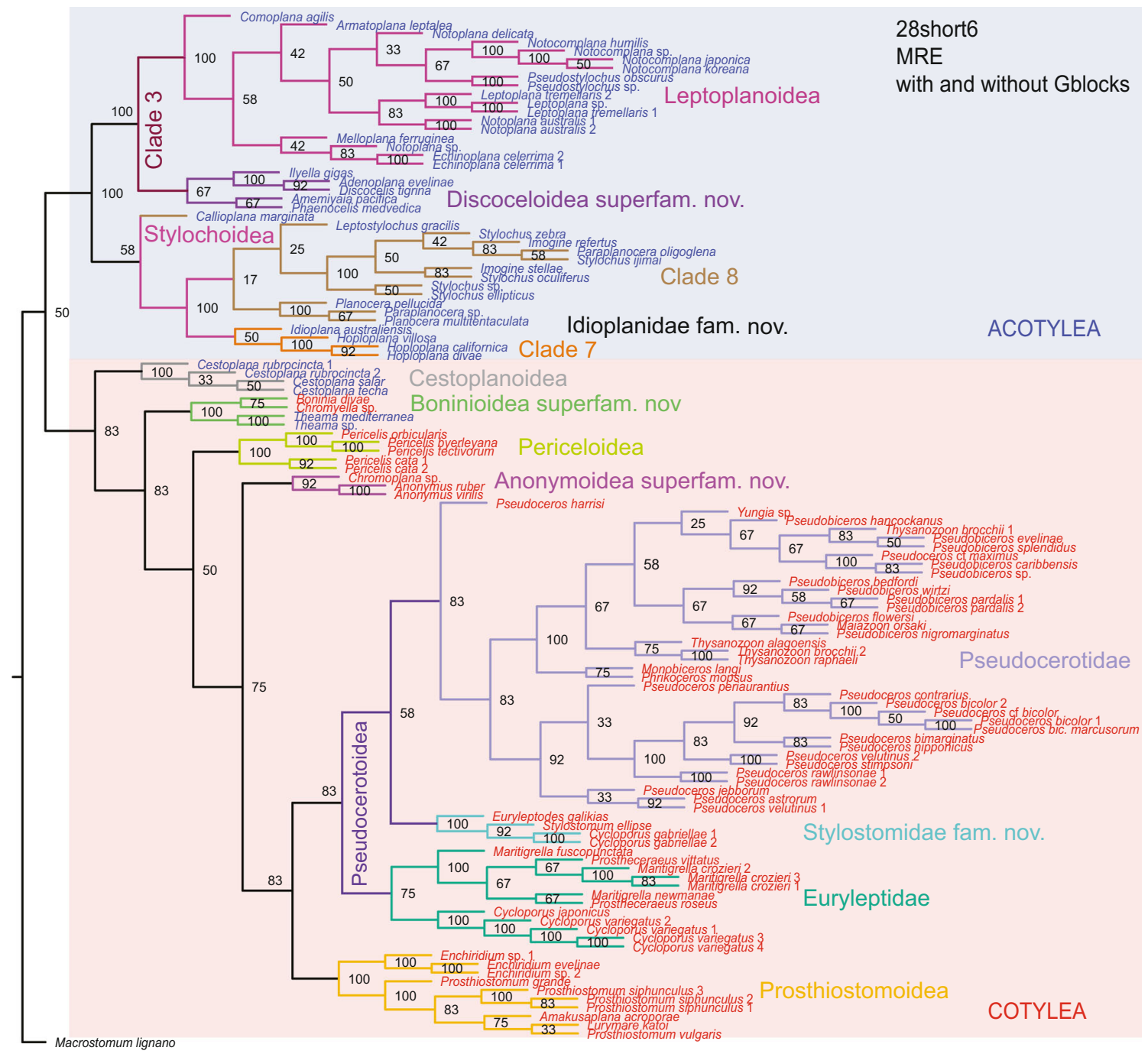

Fig. 7 Same tree as shown in Fig. 6, but with newly defined and named groups indicated. Acotylea and Cotylea sensu Faubel 1983 and 1984 are written in blue and red fonts, respectively. Species recovered as Acotylea

Prosthiostomoidea was erected by Bahia et al. (2017) and only contains a single family, Prosthiostomidae. All our data support the monophyly of this family/superfamily and most data (Table 2) also their sister group relationship to Pseudocerotoidea as described by Bahia et al. (2017). Similar to our results, also in the study of Tsunashima et al. (2017), Prosthiostomum is not monophyletic, as Amakusaplana (and in our case, also Lurymare) clusters within. In Aguado et al. (2017), two different species of Lurymare do not form an adelphotaxon. The fact that Amakusaplana clusters within Prosthiostomum is not very surprising, as Faubel (1984) remarks that the genus Amakusaplana has to be eliminated, as it is too similar to Prosthiostomum. The genus Amakusaplana is distinguished from Prosthiostomum mainly by body shape and the arrangement of eyes (Kato 1938; Faubel 1984), and also by the absence of the ventral sucker (Kato 1938; Rawlinson et al. 2011). Only in two of twelve 28Sshort6 reconstructions is Prosthiostomum monophyletic (Suppl. Figs. S17, 23), and Litvaitis et al. (2019) or Cotylea in our trees are displayed with blue and red background, respectively. Branches and nodes are given the same colour as their respective taxon

synonymise Amakusaplana with Prosthiostomum. Our data support this decision. The position of Lurymare within Prosthiostomum was already assumed by Poulter (1975). He proposed a subdivision of the genus Prosthiostomum into the subgenera P. (Lurymare) and P. (Prosthiostomum), distinguishable by the constitution of the prostatic vesicle (Poulter 1975). Faubel (1984) remarks that this definition also includes Enchiridium and elevates both subgenera back as genera. At least Enchiridium may be monophyletic, as suggested by Bahia et al. (2017), Litvaitis et al. (2019) and our own trees. Together, the molecular phylogenies do not support any of the previously proposed genera (Kato 1938; Poulter 1975; Faubel 1984) except Enchiridium, i.e. the revision of the genera Prosthiostomum and Lurymare is required.

Our clade 1, consisting of Anonymus and Chromoplana, is extremely well supported and always monophyletic, except in one case, where it appears polytomic (Suppl. Fig. S21). We propose a new superfamily Anonymoidea superfam. nov. 
(Fig. 7), including the families Anonymidae (Lang 1884) and Chromoplanidae (Bock 1922).

Cestoplanoidea was defined by Poche (1926), emended by Prudhoe (1985) and supported by Bahia et al. (2017) and Litvaitis et al. (2019); a majority of the 28Sshort6, but only a minority of the 18S28Slong analyses support its sister group relationship with all other Cotylea, as suggested by Rawlinson and Stella (2012) and Bahia et al. (2017), even if the family was originally assigned to Acotylea (Lang 1884; Faubel 1983; Prudhoe 1985) and appears as an acotylean in a majority of the 18S28Slong analyses, as well as in Rawlinson et al. (2011). In his monograph, Faubel remarks that organisation features of Cestoplana, like the forward direction of the male complex, the multiplication of the female apparatus in Cestoplana polypora, or the presence of an adhesive organ in some (but not all) Cestoplana species, could imply that Cestoplanidae have possibly arisen from a cotylean ancestor (Laidlaw 1903; Bock 1922; Faubel 1983; Bahia et al. 2017).

In all of our reconstructions, Cestoplanoidea are monophyletic (Table 2), although the only representing genus is Cestoplana.

Periceloidea was also erected by Bahia et al. (2017) and also contains a single, monotypic family, Pericelidae. Our data support the monophyly of this group. Additionally, our 28Sshort6 MRE tree (Fig. 6) supports its sister group relationship with all remaining Cotylea except Cestoplanidae, as already assumed by Bahia et al. (2017) and Rawlinson and Stella (2012). In Tsunashima et al. (2017), Pericelis is also recovered as a cotylean, but as sister group to Boninia + Chromyella (Theamatidae), although Cestoplana is absent in Tsunashima et al.'s reconstruction. In Rawlinson et al. (2011) and our 18S28Slong MRE tree (Fig. 5), Periceloidea are grouping with Acotylea, however. Litvaitis et al. (2019) include Diposthus in their phylogenetic reconstruction, which emerges as sister group of Pericelis, and they argue for abolishing both Pericelidae and Periceloidea in favour of the family Diposthidae.

Our data do not support the following superfamilies sensu Bahia et al. (2017):

The position of Chromoplanoidea within Cotylea is supported by most of our analyses (Table 2), although in the 18S28Slong MRE tree, Chromoplanoidea is recovered as acotylean (Fig. 5). The superfamily always is monophyletic, but the interrelationships between the three included chromoplanoid genera are differently resolved. In Bahia et al. (2017), Theama + Chromyella form a sister group to Boninia, while in almost all of our trees, including the MRE trees, Chromyella + Boninia are sister group to Theama. Curiously, in the only trees of our dataset supporting Theama + Chromyella (Suppl. Figs. S13, 15, 21), we used the same alignment method (MUSCLE), the same reconstruction method (RAxML), a partial 28S matrix and Gblocks, just like Bahia et al. (2017). In Laumer and Giribet (2014, 2017), the remaining possibility is realised, i.e. Theama + Boninia are sister group to Chromyella.
Moreover, the name of the superfamily has been erected based on the oldest family of the three included genera, Theama, Chromyella and Boninia (Bahia et al. 2017). According to Bahia et al. (2017), the corresponding families of these genera are Theamatidae, Amyellidae and Chromoplanidae. Theama is a member of Theamatidae Marcus 1949, Chromyella is a member of either Amyellidae Faubel 1983 or Chromoplanidae Bock 1922, but Boninia is a member of Boniniidae Bock 1923. Also, the epynomous genus of Chromoplanidae, Chromoplana, is not clustering with Chromyella in any tree containing both of the genera (see also Laumer and Giribet 2014; Tsunashima et al. 2017). Therefore, the family name Chromoplanidae should stay with Chromoplana, and Chromyella should be retained in the family Amyellidae, making Boniniidae the oldest family of the three clustering genera. Here, we propose a new superfamily, Boninioidea superfam. nov., with the morphological definition of Chromoplanoidea sensu Bahia et al. 2017, but including the families Theamatidae, Amyellidae and Boniniidae.

Cryptoceloidea sensu Bahia et al. (2017) include the families Discocelidae (represented by Adenoplana in Bahia et al. 2017 and by Discocelis and Adenoplana in our 28Sshort6 trees), and Cryptocelidae (represented by Phaenocelis in Bahia et al. 2017, and by Cryptocelis, Phaenocelis and Amemiyaia in our 28Sshort6 trees). While Faubel (1983) puts the genus Amemiyaia into the family Stylochoplanidae, Prudhoe (1985) considers it to be a Cryptocelididae, the latter being consistent with our results (Figs. 6 and 7). Thus, we reject the family Cryptocelidae sensu Faubel (1983). Our clade 6 contains members of Discocelidae and Cryptocelididae sensu Prudhoe (1985), and with Ilyella gigas an Ilyplanidae (Faubel 1983). We therefore reject Cryptoceloidea sensu Bahia et al. (2017) as it contains Cryptocelidae sensu Faubel (1983) and redefine the superfamily with the inclusion of the family Cryptocelididae sensu Prudhoe (1985), and the families Ilyplanidae and Discocelidae. This in turn means that Discocelidae Laidlaw (1903) is the oldest family constituting the superfamily, and accordingly, the superfamily is named Discoceloidea, including the families Cryptocelididae, Discocelidae and Ilyplanidae.

Stylochoidea sensu Bahia et al. (2017) has nuchal tentacles in common and includes the families Hoploplanidae, Stylochidae, Pseudostylochidae and Planoceridae. Faubel (1984) placed the genus Hoploplana within Leptoplanoidea, mainly due to the presence of an interpolated prostatic vesicle. This is in contrast to Prudhoe (1985), who considered the genus to be part of Planoceridae and thus in the superfamily Stylochoidea. Hoploplana was sister to Planocera within Stylochoidea in Bahia et al. (2017) and Litvaitis et al. (2019). Also Aguado et al. (2017) proposed the inclusion of Hoploplana in Stylochoidea based on the morphological differences of the prostatic vesicle (also see Noreña et al. 2015) between leptoplanoids and that of Hoploplana, as well as on their molecular phylogeny. Our 28Sshort6 MRE tree supports the sister group relationship of Hoploplana with the pseudostylochid Idioplana (Fig. 6), while 
there is strong support of Hoploplana + Planocera in our 18S28Slong trees, where Idioplana is lacking (Fig. 5), but also in some of the 28Sshort6 trees (Suppl. Figs. S14, 17, 20, 23).

We reject the superfamily Stylochoidea sensu Bahia et al. (2017) in the current form, as all our 28Sshort6 trees show that the pseudostylochids Pseudostylochus sp. as well as Pseudostylochus obscurus appear within Leptoplanoidea sensu Bahia et al. (2017), thus forming our clade 5, whereas the remaining pseudostylochid, Idioplana australiensis, recovers within Stylochoidea (sensu Bahia et al. 2017), see above. Pseudostylochus is the type genus of Pseudostylochidae, so the family name is retained with the genus; consequently, we erect a new family for Idioplana, Idioplanidae fam. nov., currently with the diagnosis of the genus.

A further indication that Pseudostylochidae belongs within Leptoplanoidea sensu Bahia et al. (2017), rather than within Stylochoidea sensu Bahia et al. (2017), can be found in the study of Aguado et al. (2017). There, Pseudostylochus intermedius clusters within Leptoplanoidea (Aguado et al. 2017). The authors trace this position back to a misidentified species by Sato et al. (2001). However, we think a misidentification is unlikely, as all of our phylogenetic trees including Pseudostylochus sp. as well as Pseudostylochus obscurus confirm the position of Pseudostylochus within Leptoplanoidea — with different sampling material, and different genes than provided by Sato et al. (2001). Also, Pseudostylochus is always recovered as monophyletic. Already in the original description of the genus Pseudostylochus, it was placed within the same superfamily as Leptoplanidae, Schematommata (Yeri and Kaburaki 1918). In the study of Tsunashima et al. (2017), Pseudostylochus is shown within Notoplanidae, and hence within Leptoplanoidea as well. As Pseudostylochus has nuchal tentacles, albeit 'small and indistinct' (Yeri and Kaburaki 1918), the placement of the genus within the Leptoplanoidea (a group without nuchal tentacles) contradicts the hypothesis that nuchal tentacles have only evolved once in Polycladida, at the base of Stylochoidea (Bahia et al. 2017).

As a result, we redefine the superfamily Stylochoidea (sensu Bahia et al. 2017) consisting of Hoploplanidae, Idioplanidae nov. fam., Stylochidae and Planoceridae, but without Pseudostylochidae.

Within the family Stylochidae (represented by the genera Stylochus, Imogine, Leptostylochus), only the minority of our 28Sshort6 trees recovers the genus Stylochus as monophyletic (two of twelve), and none of our trees supports a monophyletic Imogine, corroborating the results of Aguado et al. (2017) and Bahia et al. (2017). This is not surprising, as both genera were formerly included as subgenera of Stylochus (Jennings and Newman 1996; Aguado et al. 2017). We therefore recommend to combine them in one genus-Stylochus - once more, as the name Stylochus (Ehrenberg 1831) predates the name Imogine (Girard 1853).

Additionally, Planoceridae sensu Faubel (1983) are never monophyletic in any of our 28 Sshort6 trees, because
Paraplanocera oligoglena always clusters within Stylochidae, even in our 18S28Slong trees (Table 2, Fig. 5). This phylogenetic position of Paraplanocera oligoglena corresponds to the finding of Tsunashima et al. (2017) and Bahia et al. (2017). As stated under the section 'Correct determination is important', Paraplanocera sp. is confusingly labelled as Planocera sp. in their paper (Bahia et al. 2017), but published as Paraplanocera sp. in GenBank. This Paraplanocera sp. sequence renders the genus Planocera paraphyletic in most of our 28Sshort6 trees (Table 2).

Leptoplanoidea sensu Bahia et al. (2017) includes Pleioplanidae, Leptoplanidae, Notoplanidae and Stylochoplanidae. As discussed above (in Stylochoidea sensu Bahia et al. 2017), we also have to reject this superfamily in its current form, as Pseudostylochidae (represented by Pseudostylochus) clusters in all of our 28Sshort6 trees within Leptoplanoidea. Hence, the group including Pleioplanidae, Leptoplanidae sensu Prudhoe 1985 (excluding Hoploplana), Notoplanidae, Stylochoplanidae and Pseudostylochidae is to be called Leptoplanoidea.

Within Leptoplanoidea, Stylochoplanidae sensu Faubel (1983) (including Amemiyaia, Comoplana and Armatoplana) appears polyphyletic in all of our 28Sshort6 trees (see Discussion about Cryptoceloidea), strongly suggesting the need of revision of the family. The only other molecular study including more than one member of Stylochoplanidae is Aguado et al. (2017), in which mitochondrial sequences of Stylochoplana maculata and Comoplana agilis were used, which did not appear as sister groups in their phylogenetic reconstruction. However, the published sequence of $S$. maculata was found to be almost identical to the sequence of Leptoplana tremellaris, leading the authors to suggest that $S$. maculata was possibly misidentified and is actually L. tremellaris (Aguado et al. 2017).

All our 28Sshort6 trees show that Leptoplanidae (sensu Faubel 1983 or Prudhoe 1985), Notoplanidae (sensu Faubel 1985) and Notoplana are not monophyletic, while Notocomplana and Leptoplana are always monophyletic. In Tsunashima et al. (2017), as well as in Bahia et al. (2017), Notoplanidae are not monophyletic as well. In their recently published phylogenetic reconstruction, Litvaitis et al. (2019) revised several families and genera within this superfamily.

\section{Conclusions}

Success in resolving polyclad interrelationships was hampered so far by different approaches using different genes or different parts of the same gene, making a combination of published data difficult. Polyclad interrelationships are still only tentatively resolved using single or two gene phylogenies. We have identified some stable parts of the phylogeny, and also groups which need to be revisited with better taxon sampling and with longer alignments, ideally using a transcriptomic-phylogenomic approach. 
Acknowledgements We are grateful to Miquel Vila-Farré, Alexandra Grosbusch, Lucy Neumann, Tamara Schadt, Tania Holtzem, Florian Holler and Philip Bertemes for their assistance with sampling. We additionally thank the Research Focal Point Scientific Computing at the University of Innsbruck for providing computing infrastructure for assemblies, and the University of Innsbruck for supporting ILD with a 'Stipendium für kurzfristige wissenschaftliche Arbeiten im Ausland' and a PhD fellowship, and $\mathrm{BE}$ with a grant for young academics. This research received support from the SYNTHESYS Project http://www. synthesys.info/ (ES-TAF-3940 and ES-TAF-4482) which is financed by European Community Research Infrastructure Action under the FP6 "Structuring the European Research Area" Programme and the FP7 "Capacities" Program at the Museo Nacional de Ciencias Naturales Madrid (CSIC).

Funding Information Open access funding provided by University of Innsbruck and Medical University of Innsbruck.

Open Access This article is distributed under the terms of the Creative Commons Attribution 4.0 International License (http:// creativecommons.org/licenses/by/4.0/), which permits unrestricted use, distribution, and reproduction in any medium, provided you give appropriate credit to the original author(s) and the source, provide a link to the Creative Commons license, and indicate if changes were made.

\section{References}

Aguado, M. T., \& Bleidorn, C. (2010). Conflicting signal within a single gene confounds syllid phylogeny (Syllidae, Annelida). Molecular Phylogenetics and Evolution, 55(3), 1128-1138.

Aguado, M. T., Noreña, C., Alcaraz, L., Marquina, D., Brusa, F., Damborenea, C., Almon, B., Bleidorn, C., \& Grande, C. (2017). Phylogeny of Polycladida (Platyhelminthes) based on mtDNA data. Organisms Diversity \& Evolution, 17(4), 767-778.

Altschul, S. F., Gish, W., Miller, W., Myers, E. W., \& Lipman, D. J. (1990). Basic local alignment search tool. Journal of Molecular Biology, 215, 403-410.

Álvarez-Presas, M., Baguñà, J., \& Riutort, M. (2008). Molecular phylogeny of land and freshwater planarians (Tricladida, Platyhelminthes): From freshwater to land and back. Molecular Phylogenetics and Evolution, 47(2), 555-568.

Bahia, J., Padula, V., Correia, M. D., \& Sovierzoski, H. H. (2015). First records of the order Polycladida (Platyhelminthes, Rhabditophora) from reef ecosystems of Alagoas State, north-eastern Brazil, with the description of Thysanozoon alagoensis sp. nov. Journal of the Marine Biological Association of the United Kingdom, 95(8), 1653-1666.

Bahia, J., \& Schroedl, M. (2016). Pseudobiceros wirtzi sp. nov. (Polycladida: Cotylea) from Senegal with revision of valid species of the genus. Zootaxa, 4097(1), 101-117.

Bahia, J., Padula, V., \& Schrödl, M. (2017). Polycldida phylogeny and evolution: Integrating evidence from 28S rDNA and morphology. Organisms Diversity \& Evolution, 17, 653-678.

Blanchard, E. (1847). Recherches sur l'organisation des vers. Annales des Sciences Naturelles. Troisième série. Zoologie, 8, 271-275.

Bock, S. (1913). Studien über Polycladen. Zoologiska Bidrag från Uppsala, 2, 31-344.

Bock, S. (1922). Two new Cotylean genera of Polyclads from Japan and remarks on some other Cotyleans. Ark. Zool. v. 14 n. 13, p. 1-31 t. 1-2. Stockholm.

Bock, S. (1923). Boninia, a new polyclad genus from the Pacific. Nov Act R Soc Sci Uppsala, 6, 1-32.
Bolaños, D. M., Quiroga, S. Y., \& Litvaitis, M. K. (2007). Five new species of cotylean flatworms (Platyhelminthes: Polycladida) from the wider Caribbean. Zootaxa, 1650(1), 1-23.

Bulnes, N. V., \& Torres, Y. (2014). Pseudoceros astrorum, a new species of Polycladida (Cotylea, Pseudocerotidae) from northeastern Brazil. Zootaxa, 3881(1), 94-100.

Castresana, J. (2000). Selection of conserved blocks from multiple alignments for their use in phylogenetic analysis. Molecular Biology and Evolution, 17, 540-552.

Casu, M., Scarpa, F., Delogu, V., Cossu, P., Lai, T., Sanna, D., \& CuriniGalletti, M. (2014). Biodiversity patterns in interstitial marine microturbellaria: A case study within the genus Parotoplana (Platyhelminthes: Rhabditophora) with the description of four new species. Journal of Zoological Systematics and Evolutionary Research, 52(3), 190-202.

Chen, H., Rangasamy, M., Tan, S. Y., Wang, H., \& Siegfried, B. D. (2010). Evaluation of five methods for total DNA extraction from western corn rootworm beetles. PLoS One, 5(8), e11963.

Collingwood, D. (1876). VI. On thirty-one species of marine planarians, collected partly by the late Dr. Kelaart, FLS, at Trincomalee, and partly by Dr. Collingwood, FLS, in the eastern seas. Transactions of the Linnean Society of London. 2nd Series: Zoology, 1(3), 83-98.

Cuadrado, D., Moro, L., \& Noreña, C. (2017). The Polycladida (Platyhelminthes) of the Canary Islands. New genus, species and records. Zootaxa, 4312(1), 038-068.

Curini-Galletti, M., Campus, P., \& Delogu, V. (2008). Theama mediterranea sp. nov. (Platyhelminthes, Polycladida), the first interstitial polyclad from the Mediterranean. Italian Journal of Zoology, $75(1), 77-83$.

Dalyell, J. P. (1853). Observations on some interesting phenomena in animal physiology, exhibited by several species of planaria. Archibald Constable, Edinburgh.

Delle Chiaje, S. (1822-1829). Memorie sulla storia e notomia degli animali senza vertebre del regno di Napoli. Atlas of 109 Tables (1822); Vol. I (1823): 1-184; Vol. II (1825) 1,-444; Vol. III (1828) 1,-232; Vol. IV (1829) 1-214 Fratelli Fernandes, Napoli.

Dittmann, I. L., Dibiasi, W., Noreña, C., \& Egger, B. (2019). Description of the snail-eating flatworm in marine aquaria, Pericelis tectivorum sp. nov. (Polycladida, Platyhelminthes). Zootaxa, 4565(3), 383-397.

Du Bois-Reymond Marcus, E. (1957). On Turbellaria. Anais da Academia Brasileira de Ciências, 29(1), 153-191.

Du Bois-Reymond Marcus, E. (1965). Drei neue neotropische Turbellaria. Sitzungsberichte der Gesellschaft naturforschender Freunde zu Berlin, 5, 129-135.

Edgar, R. C. (2004). MUSCLE: Multiple sequence alignment with high accuracy and high throughput. Nucleic Acids research., 32(5), 1792-1797.

Egger, B., Lapraz, F., Tomiczek, B., Müller, S., Dessimoz, C., Girstmair, J., Skunca, N., Rawlinson, K. A., Cameron, C. B., Beli, E., Todaro, M. A., Gammoudi, M., Noreña, C., \& Telford, M. J. (2015). A transcriptomic-phylogenomic analysis of the evolutionary relationships of flatworms. Current Biology, 25, 1-7.

Ehrenberg, C. G. (1831). Phytozoa Turbellaria africana et asiatica. In: Hemprich und Ehrenberg "Symbolae physicae." Animalia evertebrata exclusis insectis recensuit Dr. CG Ehrenberg. Series prima cum tabularum decade prima. Berolini, Fol. Phytozoa Turbellaria folia a-d, T4-5 [plates 4, 5 published in 1828]

Faubel, A. (1983). The Polycladida, Turbellaria; proposal and establishment of a new system. Part I. The Acotylea. Mitteilungen aus dem Hamburgischen Zoologischen Museum und Institut, 80, 17-121.

Faubel, A. (1984). The Polycladida, Turbellaria proposal and establishment of a new system. Part II. The Cotylea. Mitteilungen aus dem Hamburgischen Zoologischen Museum und Institut, 81, 189-259.

Girard, C. (1850). Descriptions of several new species of marine planariae from the coast of Massachusetts. In Proceedings of the Boston Society of Natural History, 3, 251-256. 
Girard, C. F. (1853). Descriptions of new nemerteans and planarians from the coast of the Carolinas. Proceedings of the Academy of Natural Sciences of Philadelphia, 6, 365-367.

Glez-Peña, D., Gómez-Blanco, D., Reboiro-Jato, M., Fdez-Riverola, F., Posada, D. (2010). ALTER: Program-oriented format conversion of DNA and protein alignments. Nucleic Acids Research. Web Server issue. ISSN: 0305-1048.

Grube, A. E. (1840). Actinien, Echinodermen und Würmer des Adriatischen- und Mittelmeers, nach eigenen Sammlungen beschrieben. JH Bon, Königsberg, 92 pp.

Haswell, W. A. (1907). Observations on Australian polyclads. Transactions of the Linnean Society, London, 9, 465-485.

Hyman, L. H. (1939). Acoel and polyclad turbellarians from Bermuda and the Sargassum. Bulletin of the Bingham Oceanographic Collection, 7: 1-26. Art.I.

Hyman, L. H. (1951). The Invertebrates: Vol. II. Platyhelminthes and Rhynchocoela; the acelomate Bilateria. New York: McGraw-Hill $572 \mathrm{pp}$.

Hyman, L. H. (1953). The polyclad flatworms of Tsunathe Pacific coast of North America. Bulletin of the American Museum of Natural History, 100, 265-392.

Janssen, T., Vizoso, D. B., Schulte, G., Littlewood, D. T. J., Waeschenbach, A., \& Schärer, L. (2015). The first multi-gene phylogeny of the Macrostomorpha sheds light on the evolution of sexual and asexual reproduction in basal Platyhelminthes. Molecular Phylogenetics and Evolution, 92, 82-107.

Jennings, K. A., \& Newman, L. J. (1996). Two new stylochid flatworms (Platyhelminthes: Polycladida) from the Southern Great Barrier Reef, Australia. Raffles Bulletin of Zoology, 44(1), 135-142.

Jacubowa, L. (1906). Polycladen von Neu-Britannien und NeuCaledonien. Jenaische Zeitschrift für die gesammten Naturwissenschaft, 41, 113-158.

Kaburaki, T. (1923) The polyclad turbellarians from the Philippine Islands. Smithsonian Institution United States National Museum Bulletin 100 (volume I, part 10):635-649.

Kato, K. (1934). Leptostylochus gracilis, a new polyclad turbellarian. Proceedings of the Imperial Academy, 10(6), 374-377.

Kato K. (1937a). Polyclads collected in Idu, Japan. Japanese Journal of Zoology, 7, 211-232.

Kato, K. (1937b). Polyclads from Korea. Japanese Journal of Zoology, 7 , 233-240.

Kato, K. (1938). Polyclads from Seto, Middle Japan. Japanese Journal of Zoology, 7, 577-593.

Kato, K. (1944). Polycladida of Japan. The Journal of the Sigenkagaku Kenkyusyo, 1, 257-318.

Katoh, K., \& Standley, D. M. (2013). MAFFT multiple sequence alignment software version 7: Improvements in performance and usability. Molecular Biology and Evolution, 30, 772-780.

Ladurner, P., Scharer, L., Salvenmoser, W., Rieger, R. M. (2005). A new model organism among the lower Bilateria and the use of digital microscopy in taxonomy of meiobenthic Platyhelminthes: Macrostomum lignano, n. sp. (Rhabditophora, Macrostomorpha). Journal of Zoological Systematics and Evolutionary Research 43 (2):114-126

Laidlaw, F. F. (1903). Suggestions for a revision of the classification of the polyclad Turbellaria. Memoirs and proceedings of the Manchester Literary \& Philosophical Society, 48(4), 1-16.

Laidlaw, F.F. (1904). Notes on some polyclad Turbellaria in the British Museum. Memoirs and Proceedings of the Manchester Literature and Philosophical Society 48 (Art. 15) 16.

Lang, A. (1884). Die Polycladen (Seeplanarien) des Golfes von Neapel und der angrenzenden Meeresabschnitte. Eine Monographie. Fauna und Flora des Golfes von Neapel. W. Engelmann, Leipzig.

Larsson, K., \& Jondelius, U. (2008). Phylogeny of Catenulida and support for Platyhelminthes. Organisms Diversity \& Evolution, 8(5), 378-387.
Laumer, C. E., \& Giribet, G. (2014). Inclusive taxon sampling suggests a single, stepwise origin of ectolecithality in Platyhelminthes. Biological Journal of the Linnean Society, 111(3), 570-588.

Laumer, C. E., Hejnol, A., \& Giribet, G. (2015). Nuclear genomic signals of the 'microturbellarian' roots of platyhelminth evolutionary innovation. eLife, 4(e05503), 1-31.

Laumer, C. E., \& Giribet, G. (2017). Phylogenetic relationships within Adiaphanida (phylum Platyhelminthes) and the status of the crustacean-parasitic genus Genostoma. Invertebrate Biology, 136(2), 184-198.

Litvaitis, M. K., \& Newman, L. J. (2001). A molecular framework for the phylogeny of the Pseudocerotidae (Platyhelminthes, Polycladida). Hydrobiologia, 444(1-3), 177-182.

Litvaitis, M. K., Bolaños, D. M., Quiroga, S. Y. (2010) When names are wrong and colours deceive: unravelling the species complex (Turbellaria: Polycladida). Journal of Natural History 44(13-14), 829-845

Litvaitis, M. K., Bolaños, D. M., \& Quiroga, S. Y. (2019). Systematic congruence in Polycladida (Platyhelminthes, Rhabditophora): Are DNA and morphology telling the same story? Zoological Journal of the Linnean Society, 186, 865-891.

Lockyer, A. E., Olson, P. D., \& Littlewood, D. T. J. (2003). Utility of complete large and small subunit rRNA genes in resolving the phylogeny of the Neodermata (Platyhelminthes): Implications and a review of the cercomer theory. Biological Journal of the Linnean Society, 78(2), 155-171.

Marcus, E. (1947). Turbellarios Marinhos do Brasil (5). Boletim da Facultade de Filosofia, Ciências e Letras Zoologia, 12, 99-215.

Marcus, E. (1949). Turbellaria brasileiros (7). Boletim da Facultade de Filosofia, Ciencias e Letras Zoologia, 14, 7-155.

Marcus, E. (1950). Turbellaria brasileiros (8). Boletim da Facultade de Filosofia, Ciências e Letras Zoologia, 15, 5-191.

Marcus, E. (1952). Turbellaria brasileiros (10). Boletim da Facultade de Filosofia, Ciências e Letras Zoologia, 17, 5-186.

Marcus, E., \& Marcus, E. (1966). Systematische Übersicht der Polycladen. Zoologische Beiträge, 12, 319-343.

Marcus, B. R., \& Marcus, E. (1968). Polycladida from Curaçao and faunistically related regions. Studies on the Fauna of Curaçao and other Caribbean Islands, 26(1), 1-133.

Marquina, D., Osca, D., Rodriguez, J., Fernandez-Despiau, E., \& Noreña, C. (2014). State of knowledge of the Acotylea (Polycladida, Platyhelminthes) from the Mediterranean coasts of Spain: New records and new species. Zootaxa, 3780(1), 108-134.

Martín-Durán, J. M., \& Egger, B. (2012). Developmental diversity in free-living flatworms. EvoDevo, 3(1), 7.

Meixner, A. (1907). Polycladen von der Somaliküste, nebst einer Revision der Stylochinen. Zeitschrift für Wissenschaftliche Zoologie, 88, 385-498.

Mertens, H. (1833). Untersuchungen über den inneren Bau verschiedener in der See lebender Planarien. Memories Academy Science St. Petersbourg, Series 6, 2, 3-17.

Montagu, G. (1813). I. Descriptions of several new or rare animals, principally marine, discovered on the South Coast of Devonshire. Transactions of the Linnean Society of London, 11(1), 1-26.

Müller, O.F. (1773). Vermivm terrestrium et fluviatilium, seu animalium Infusoriorum, Helminthicorum et Testaceorum, non marinorum succincta historia. Havniae et Lipsiae: Apud Heineck et Faber, Typis Martinus Hallager, 1773-1774. Vol I, Part 1, 1-80.

Newman, L. J., \& Cannon, L. R. G. (1994). Pseudoceros and Pseudobiceros (Platyhelminthes, Polycladida, Pseudocertotidae) from eastern Australia and Papua New Guinea. Memoirs of the Queensland Museum, 37(1), 205-266.

Newman, L. J., \& Cannon, L. R. G. (1995). The importance of the fixation of colour, pattern and form in tropical Pseudocerotidae (Platyhelminthes, Polycladida). Hydrobiologia, 305(1), 141-143. 
Newman, L. J., \& Cannon, L. R. G. (1996). New genera of pseudocerotid flatworms (Platyhelminthes; Polycladida) from Australian and Papua New Guinean coral reefs. Journal of Natural History, 30(10), 1425-1441.

Newman, L. J., \& Cannon, L. R. G. (1997). Nine new species of Pseudobiceros (Platyhelminthes: Polycladida) from the IndoPacific. The Raffles Bulletin of Zoology, 45(2), 341-368.

Newman, L. J., \& Cannon, L. R. G. (1998). Pseudoceros (Platyhelminthes: Polycladida) from the Indo-Pacific with twelve new species from the Australia and Papua New Guinea. The Raffles Bulletin of Zoology, 46(2), 293-323.

Noreña, C., Marquina, D., Perez, J., \& Almon, B. (2014). First records of Cotylea (Polycladida, Platyhelminthes) for the Atlantic coast of the Iberian Peninsula. ZooKeys, 404, 1-22.

Noreña, C., Rodríguez, J., Pérez, J., \& Almón, B. (2015). New Acotylea (Polycladida, Platyhelminthes) from the east coast of the North Atlantic Ocean with special mention of the Iberian littoral. Zootaxa, 4039(1), 157-172.

Poche, F. (1926). Das System der Platodaria. Archiv für Naturgeschichte, $91,1-458$.

Poulter, J. L. (1975). Hawaiian polyclad flatworms: Prosthiostomids. Pacific Science., 29, 317-339.

Posada, D. (2008). jModelTest: Phylogenetic model averaging. Molecular Biology and Evolution, 25(7), 1253-1256.

Prudhoe, S. (1978). Some polyclad turbellarians new to the fauna of the Australian coasts. Records of the Australian Museum, 31, 586-604.

Prudhoe, S. (1985). A monograph on Polyclad Turbellaria. London: British Museum of Natural History and Oxford University Press $259 \mathrm{pp}$.

Puslednik, L., \& Serb, J. M. (2008). Molecular phylogenetics of the Pectinidae (Mollusca: Bivalvia) and effect of increased taxon sampling and outgroup selection on tree topology. Molecular Phylogenetics and Evolution, 48(3), 1178-1188.

Rawlinson, K. A. (2008). Biodiversity of coastal polyclad fsatworm assemblages in the wider Caribbean. Marine Biology, 153, 769-778.

Rawlinson, K. A., \& Litvaitis, M. K. (2008). Cotylea (Polycladida): A cladistic analysis of morphology. Invertebrate Biology, 127(2), 121138.

Rawlinson, K. A., Gillis, J. A., Billings, R. E., \& Borneman, E. H. (2011). Taxonomy and life history of the Acropora-eating flatworm Amakusaplana acroporae nov. sp. (Polycladida: Prosthiostomidae). Coral Reefs, 30(3), 693.

Rawlinson, K. A., \& Stella, J. S. (2012). Discovery of the corallivorous polyclad flatworm, Amakusaplana acroporae, on the Great Barrier Reef, Australia: The first report from the wild. PLoS One, 7, e42240.

Risso, A. (1818). Mémoire sur quelques gastéropodes nouveaux, nudibranches et tectibranches observés dans la Mer de Nice. Journal de Physique, de Chimie, d'Histoire Naturelle et des Arts, 87, 368-377.

Ronquist, F., Teslenko, M., van der Mark, P., Ayres, D. L., Darling, A., Höhna, S., Larget, B., Liu, L., Suchard, M. A., \& Huelsenbeck, J. P. (2012). MrBayes 3.2: Efficient Bayesian phylogenetic inference and model choice across a large model space. Systems Biology, 61, 539542 .

Sambrook, J., Fritsch, E. F., Maniatis, T. (1989). Molecular cloning: A laboratory manual (2nd ed.). Cold Spring Harbor: Cold Spring Harbor Laboratory Press 1626 pp.

Sato, K., Sugita, T., Kobayashi, K., Fujita, K., Fujii, T., Matsumoto, Y., Mikami, T., Nishizuka, N., Nishizuka, S., Shojima, K., Suda, M., Takahashi, G., Himeno, H., Muto, A., \& Ishida, S. (2001). Localization of mitochondrial ribosomal RNA on the chromatoid bodies of marine planarian polyclad embryos. Development, Growth \& Differentiation, 43, 107-114.

Scarpa, F., Cossu, P., Sanna, D., Lai, T., Norenburg, J. L., Curini-Galletti, M., \& Casu, M. (2015). An 18S and 28S-based clock calibration for marine Proseriata (Platyhelminthes). Journal of Experimental Marine Biology and Ecology, 463, 22-31.

Scarpa, F., Cossu, P., Lai, T., Sanna, D., Curini-Galletti, M., \& Casu, M. (2016). Meiofaunal cryptic species challenge species delimitation: The case of the Monocelis lineata (Platyhelminthes: Proseriata) species complex. Contributions to Zoology, 85(2), 123-145.

Scarpa, F., Cossu, P., Delogu, V., Lai, T., Sanna, D., Leasi, F., Norenburg, J. L., Curini-Galletti, M., \& Casu, M. (2017). Molecular support for morphology-based family-rank taxa: The contrasting cases of two families of Proseriata (Platyhelminthes). Zoologica Scripta, 46(6), 753-766.

Schmarda, L. K. (1859). Neue wirbellose Thiere beobachtet und gesammelt auf einer Reise 1853 bis 1857. Band I. Turbellarien, Rotatorien und Anneliden. Erste Hälfte. W. Engelmann, Leipzig. $66 \mathrm{pp}$, tab 1-8.

Stamatakis, A. (2014). RAxML version 8: A tool for phylogenetic analysis and post-analysis of large phylogenies. Bioinformatics, 30, $1312-1313$.

Stocsits, R. R., Letsch, H., Hertel, J., Misof, B., \& Stadler, P. F. (2009). Accurate and efficient reconstruction of deep phylogenies from structured RNAs. Nucleic Acids Research, 37, 6184-6193.

Stimpson, W. (1857). Prodromus descriptionis animalium evertebratorum quae in Expeditione ad Oceanum Pacificum Septentrionalem, Johanne Rodgers Duce a Republica Federata missa, observavit et descripsit. Pars. I. Turbellaria Dendrocoela. Proceedings of the Academy of Natural Sciences of Philadelphia, 9, 19-31.

Tan, G., Muffato, M., Ledergerber, C., Herrero, J., Goldman, N., Gil, M., \& Dessimoz, C. (2015). Current methods for automated filtering of multiple sequence alignments frequently worsen single-gene phylogenetic inference. Systematic Biology, 64(5), 778-791.

Tessens, B., Janssen, T., \& Artois, T. (2014). Molecular phylogeny of Kalyptorhynchia (Rhabdocoela, Platyhelminthes) inferred from ribosomal sequence data. Zoologica Scripta, 43(5), 519-530.

Tsunashima, T., Hagiya, M., Yamada, R., Koito, T., Tsuyuki, N., Izawa, S., Kosoba, K., Itoi, S., \& Sugita, H. (2017). A molecular framework for the taxonomy and systematics of Japanese marine turbellarian flatworms (Platyhelminthes, Polycladida). Aquatic Biology, 26, $159-167$

Van Steenkiste, N., Tessens, B., Willems, W., Backeljau, T., Jondelius, U., \& Artois, T. (2013). A comprehensive molecular phylogeny of Dalytyphloplanida (Platyhelminthes: Rhabdocoela) reveals multiple escapes from the marine environment and origins of symbiotic relationships. PLoS One, 8(3), e59917.

Verrill, A.E. (1882). Notice of the remarkable marine fauna occupying the outer banks off the southern coast of New England, No. 7, and of some additions to the fauna of Vineyard Sound. The American Journal of Science 24: 360 pages.

Verrill, A. E. (1900). Additions to the Turbellaria, Nemertina, and Annelida of the Bermudas, with revisions of some New England genera and species. Connecticut academy of arts and sciences.

Verrill, A. E. (1902). Additions to the fauna of the Bermudas from the Yale Expedition of 1901, with notes on other species. Transactions of the Connecticut Academy of Arts and Sciences, 11, 15-62.

Woodworth, W. M. (1898). Some Planarians from the Great Barrier Reef of Australia. Museum of Comparative Zoology.

Yeri, M., \& Kaburaki, T. (1918). Description of some Japanese polyclad Turbellaria. The Journal of the College of Science, Imperial University of Tokyo, Japan, 39, 1-54.

Publisher's note Springer Nature remains neutral with regard to jurisdictional claims in published maps and institutional affiliations. 